\title{
Proteomic analysis of low- and high-grade human colon adenocarcinoma tissues and tissue-derived primary cell lines reveals unique biological functions of tumours and new protein biomarker candidates
}

\section{Matthew J Munro}

Victoria University of Wellington

\section{Susrutha K Wickremesekera}

Gillies Mclndoe Research Institute

Swee T Tan

Gillies Mclndoe Research Institute

Lifeng Peng ( $\square$ lifeng.peng@vuw.ac.nz)

Victoria University of Wellington

\section{Research Article}

Keywords: biomarker, colon adenocarcinoma, colorectal cancer, label-free quantitation, proteomics

Posted Date: March 7th, 2022

DOI: https://doi.org/10.21203/rs.3.rs-1420689/v1

License: (c) (i) This work is licensed under a Creative Commons Attribution 4.0 International License. Read Full License 


\section{Abstract}

Background: Colon cancer is the third most common cancer and second highest cause of cancer deaths worldwide. The aim of the study was to find new biomarkers for diagnosis, prognosis and therapeutic drug targets for this disease.

Methods: Four low-grade and four high-grade human colon adenocarcinoma tumours with patientmatched normal colon tissues were analysed. Additionally, tissue-derived primary cell lines were established from each tumour tissue. The cell lines were validated using DNA sequencing to confirm that they are a suitable in vitro model for colon adenocarcinoma based on conserved gene mutations. Labelfree quantitation proteomics was performed to compare the proteomes of colon adenocarcinoma samples to normal colon samples, and of colon adenocarcinoma tissues to tissue-derived cell lines to find significantly differentially abundant proteins. The functions enriched within the differentially expressed proteins were assessed using STRING. Proteomics data was validated by Western blotting.

Results: A total of 4767 proteins were identified across all tissues, and 4711 across primary tissue-derived cell lines. Of these, 3302 proteins were detected in both the tissues and the cell lines. On average, primary cell lines shared about $70 \%$ of proteins with their parent tissue, and they retained mutations to key colon adenocarcinoma-related genes and did not diverge far genetically from their parent tissues. Colon adenocarcinoma tissues displayed upregulation of RNA processing, steroid biosynthesis during tumour initiation and immune system responses and detoxification during tumour progression, downregulation of cytoskeletal organisation and loss of normal muscle function. Tissue-derived cell lines exhibited increased interferon-gamma signalling and aberrant ferroptosis. Overall, 318 proteins were significantly up-regulated and 362 proteins down-regulated by comparisons of high-grade with low-grade tumours and low-grade tumour with normal colon tissues from both sample types.

Conclusions: The differences exhibited between tissues and cell lines highlight the additional information that can be obtained from patient-derived primary cell lines. DNA sequencing and proteomics confirmed that these cell lines can be considered suitable in vitro models of the parent tumours. Various potential biomarkers for colon adenocarcinoma initiation and progression and drug targets were identified and discussed, including ten novel markers ACSL4, ANK2, AMER3, CAV3, EXOSC6, EXOSC6, GCLM, LDB3, MUC5B and TRFC.

\section{Background}

Colorectal cancer (CRC) is the third most common cancer type, accounting for $10 \%$ of new cancer cases in 2020, and the second highest cause of cancer deaths (1). Colon adenocarcinoma (CA) accounts for $90 \%$ of CRC cases (2). CA grading has generally used a 2-tier system with low-grade CA (LGCA) comprising both well and moderately differentiated tumours, and poorly differentiated tumours regarded as high-grade CA (HGCA) (2). 
Mutation of the $A P C$ gene is considered the initiating event of CRC development $(3,4)$. Activating mutations of KRAS and deactivating mutations of TP53 and SMAD4 are also common in CRC, and their sequential accumulation contributes to the adenoma-carcinoma sequence of disease progression (5). Metastasis is primarily driven by local invasion and subsequent entry of tumour cells into blood vessels located in or near the tumour, which then move through the circulation until they become trapped or adhere to capillaries in distant organs (6). This movement is enabled by reduced cell adhesion and increased proteolysis (7).

CRC is typically diagnosed late due to it being asymptomatic at earlier stages of disease progression. Diagnosis is typically made by colonoscopy to visualise polyps or tumours, or faecal occult blood tests to detect blood in the stool (8). Serum levels of carcinoembryonic antigen (CEA) are used as a prognostic tool for CRC patients and to indicate recurrence after surgery with $80 \%$ sensitivity and $70 \%$ specificity (9), although it can also be elevated in bowel inflammation, liver disease and pancreatitis (10). An alternative blood test based on cell-free DNA, which is thought to be more abundant in cancer patients than healthy individuals, is in development (11). Further pathologic testing is carried out by interrogating KRAS, NRAS and $B R A F$ mutations and testing for mismatch repair (MMR) defects or microsatellite instability (MSI) (12). MSI status has prognostic value, with MSI-H patients having better outcomes than microsatellite stable patients.

There is a need for more reliable, non-invasive and specific biomarkers to enhance detection of earlystage CRC, and treatments that target the mechanisms enabling CRC progression. Recently, there has been a focus on employing proteomics to identify CRC biomarkers. Interrogation of liquid biopsies from patients (13-15) identified fibronectin (FN1) and S100A9 as potential markers of CRC progression, and proposed that the combination of S100A9 and tenascin-C with CEA is superior to CEA alone as a CRC biomarker. A range of secretome and exosome biomarkers have been proposed, including C3a, APOC1, SERPINA1 and TSPAN1 (15-17). Proteomics has been used to search of markers of metastasis by comparing the proteomes of primary CRC to liver metastases (18-20), to identify markers of cancer initiation or progression (21-24), and to interrogate untreated versus treated CRC to determine the effects of treatment on the global proteome (25). Studies combining proteomics with genomics or transcriptomics have been performed on colon cancer tissue samples (26-31). Commercial cell lines are often utilised for proteomic analyses (32-42), but primary tumour-derived cell lines are less common. Recently, patient-derived organoids have emerged as a new tool for studying colon cancer proteomics (43-46).

In this study, we analysed tumour tissue samples from 4 LGCA patients and 4 HGCA patients and their corresponding patient-matched NC tissue samples. Furthermore, primary cell lines were derived from these 8 CA tissue samples. Label-free quantitation (LFQ) proteomics $(47,48)$ was utilised to characterise the proteomes of the samples. The aims of this study were to characterise cell lines derived from colon tumour tissue in comparison with their tissues of origin, and to identify novel potential biomarkers and drug targets of CRC at tumour initiation and progression. The primary cell lines were validated using DNA sequencing and proteomics by comparison to their parental tissues. Differentially expressed proteins, 
measured by liquid chromatography tandem mass spectrometry (LC-MS/MS), were determined based on the confidence of protein identification and statistically significant changes in abundance between the patient-matched adjacent normal colon (NC) and LGCA and between LGCA and HGCA. The functional enrichments associated with these changes in the gene ontology (GO) terms, Kyoto Encyclopedia of Genes and Genomes (KEGG) and Reactome pathways were analysed to evaluate the samples at the system level. The proteomes and functional implications were also compared between CA tissues and CA-derived primary cell lines.

\section{Materials And Methods}

\section{Human colon tissue samples and tissue-derived primary cell lines}

Formalin-fixed paraffin-embedded (FFPE) and snap-frozen tissue samples from 4 LGCA patients and 4 HGCA patients, with 8 patient-matched adjacent NC samples (4 from LGCA patients and 4 from HGCA patients), were provided by the Gillies Mclndoe Research Institute Tissue Bank (GMRITB) for this study, which was approved by the Central Health and Disability Ethics Committee, Wellington, NZ (Ref. 15/CEN/96) with written informed consent from all patients. The FFPE tissue samples were used for immunohistochemical (IHC) staining. The snap-frozen tissues were used for proteomics, with a total of 16 tissue samples analysed. Patient clinical data can be found in Additional File 1.

Primary cell lines were derived from each of the CA tissues, giving 8 cell lines ( 4 from LGCA and 4 from HGCA) from different donors. Cell lines were provided by GMRITB at passage number 4 - 5 and were subcultured to a passage number not higher than 9 for experiments. Cells were cultured in Nunc ${ }^{\mathrm{Tm}}$ EasYFlasks $^{\text {TM }}$ (ThermoFisher Scientific) using DMEM media (cat\# 10569010, ThermoFisher Scientific) supplemented with $10 \%$ fetal calf serum (cat\# 10091148, ThermoFisher Scientific), $5 \%$ mTeSR Complete (cat\# 85850, STEMCELL Technologies, Tullamarine, Victoria, Australia), 1\% penicillin-streptomycin (cat\# 15140122, ThermoFisher Scientific) and 0.2\% gentamicin/amphotericin B (cat\# R01510, ThermoFisher Scientific). Cells were passaged upon reaching 75-95\% confluency using TrypLE Express Enzyme (cat\# 12605093, ThermoFisher Scientific).

\section{Immunohistochemistry}

IHC staining was performed as previously described (49).

\section{DNA sequencing}

DNA was extracted from FFPE tissue samples and tissue-derived cells using the PureLink Genomic DNA Mini Kit (cat\# 1820-00, Invitrogen, ThermoFisher Scientific) and the quality of extracted DNA was assessed using the TaqMan ${ }^{\text {TM }}$ RNase P Detection Reagents Kit (cat\# 4316831, ThermoFisher Scientific), as per the manufacturer's instructions. DNA sequencing was performed by ThermoFisher Scientific (Life Technologies, Melbourne, Victoria, Australia) using the Oncomine ${ }^{\mathrm{TM}} \mathrm{TML}$ assay to assess the mutational signatures of key CA-related genes in the CA tissues and the CA tissue-derived primary cell lines. DNA 
sequencing data were analysed using the cloud-based lon Reporter system. Single-nucleotide variants and their impacts and tumour mutational burden were compared between FFPE tissues and the CA tissue-matched primary cell lines.

\section{Protein extraction}

Tissues and cells were lysed in lysis buffer containing $30 \mathrm{mM}$ Tris- $\mathrm{HCl}, \mathrm{pH}$ 7.4; $7 \mathrm{M}$ urea, $2 \mathrm{M}$ thiourea, and $4 \%$ CHAPS plus $1 \%$ Halt ${ }^{\mathrm{TM}}$ Protease and Phosphatase inhibitor cocktail (cat\# 78442, ThermoFisher Scientific), with a $1 \mathrm{~mL}$ glass Dounce homogeniser (Corning Inc, Corning, NY, USA) on ice. Samples were agitated for $45 \mathrm{~min}$ at $4^{\circ} \mathrm{C}$, then centrifuged at $17,000 \mathrm{~g}$ for $20 \mathrm{~min}$ at $4^{\circ} \mathrm{C}$. Protein concentration was measured by Bradford assay (Bio-Rad). The samples were stored at $-20^{\circ} \mathrm{C}$.

\section{Protein digestion and peptide purification}

Extracted proteins were precipitated using a Calbiochem ProteoExtract ${ }^{\circledR}$ Protein Precipitation Kit as per manufacturer's instructions (cat\# 539180, Merck, Auckland, NZ). The protein pellet was dissolved in a digestion buffer of $8 \mathrm{M}$ urea and $100 \mathrm{mM}$ Tris-HCl, pH 8.5. After a second Bradford assay, $20 \mu \mathrm{g}$ of protein was taken from each sample and the volume brought to $25 \mu \mathrm{L}$ using digestion buffer. Subsequently, the proteins were reduced, alkylated and digested as previously described (50, 51). The resulting tryptic peptides were purified using OMIX C18 $100 \mu \mathrm{L}$ zip-tips (cat\# A57003100K, Agilent Technologies, Santa Clara, CA, USA). Eluates were pooled and dried down using a vacuum centrifuge, then brought to $100 \mu \mathrm{L}$ using $0.1 \%$ formic acid (FA) in $3 \%$ acetonitrile (ACN).

\section{Liquid chromatography tandem mass spectrometry}

Proteomic analysis of the prepared samples was performed by LC-MS/MS using an UlitMate 3000 RSLCnano system and a high-resolution Orbitrap Fusion ${ }^{\text {TM }}$ Lumos $^{\text {TM }}$ Tribrid $^{\text {TM }}$ mass spectrometer coupled via a Nanospray Flex ion source (ThermoFisher Scientific).

Sample vials were placed in the autosampler of the HPLC unit for injection, maintained at $10^{\circ} \mathrm{C}$. Xcalibur ${ }^{\text {TM }}$ software (Version 2.1.0, ThermoFisher Scientific) was used to define the method and acquire LC-MS/MS data. Peptides were first loaded onto an Acclaim ${ }^{\mathrm{TM}}$ PepMap $^{\mathrm{TM}} 100 \mathrm{C} 18,5 \mathrm{~mm} 0.3 \times 5 \mathrm{~mm}$ trap column (cat\# 160454, ThermoFisher Scientific) with $2 \%$ ACN and $0.05 \%$ trifluoroacetic acid at a loading pump flow rate of $8.0 \mu \mathrm{L} / \mathrm{min}$, then separated on an Acclaim ${ }^{\text {TM }}$ PepMap $^{\text {TM }} 100 \mathrm{C} 18,2 \mu \mathrm{m}, 100 \mathrm{~A}, 75 \mu \mathrm{m} \times 15 \mathrm{~cm}$ analytical column (cat\# 164941, ThermoFisher Scientific) with the Nano/Cap pump running at $0.3 \mu \mathrm{L} /$ min with an organic solvent gradient constructed from buffer $\mathrm{A}(0.1 \% \mathrm{FA})$ and buffer $\mathrm{B}(0.1 \% \mathrm{FA}$ in $80 \% \mathrm{ACN})$. The gradient was programmed as follows: $3 \%$ from 0 to $5 \mathrm{~min}, 30 \%$ from $5-70 \mathrm{~min}, 50 \%$ from $70-82 \mathrm{~min}, 95 \%$ from $82-88 \mathrm{~min}$, and finally $3 \%$ from $88-99 \mathrm{~min}$. Elution was based on reversephase liquid chromatography, whereby the more hydrophobic the peptide is the slower it will pass through the column. Also, larger peptides have longer retention times. 
The peptides eluted in solution were ionised by nanoelectrospray ionisation (Nanospray Flex, ThermoFisher Scientific) with the $25 \mu \mathrm{M}$ lon Transfer capillary tube set to $275^{\circ} \mathrm{C}$ and voltage set at $1.8 \mathrm{kV}$. MS scans were acquired in the Orbitrap (OT) with the following settings: detector type OT, resolution 120,000, scan range $375-1500$ m/z, AGC target 5.0e3, Maximum Injection Time 50 ms, charge state 2 7, and data type Profile. Data-dependent MS/MS scans were acquired in lon trap having the following settings: detector type IT, scan range mode Auto: m/z Normal, IT scan rate Rapid, AGC target 5.0e3, Maximum Injection Time 300 ms, and data type Centroid. For MS/MS, high-energy collision-induced dissociation (HCD) fragmentation was performed in the linear Quadrupole ion trap (isolation window 1.6 $\mathrm{m} / \mathrm{z}$, HCD collision energy 30\%). The "Top 20" highest-intensity ions from each MS scan were selected for the subsequent MS/MS scans. Dynamic exclusion had the following settings: mass tolerance $10 \mathrm{ppm}$, exclusion duration $60 \mathrm{~s}$. Each sample was run in triplicate for LC-MS/MS.

\section{Protein identification}

Spectra were exported as raw files and searched against SwissProt human protein sequence database (TaxID=9606 and Subtaxonomies, version 2017-10-25, downloaded on 24-10-2019, 42,253 sequences) using the SequestHT search engine in Proteome Discoverer (PD; version 2.4, ThermoFisher Scientific). Protein identification settings were as follows: peptide length range 6-144, allowing 2 missed trypsin cleavages, precursor mass tolerance $10 \mathrm{ppm}$, fragment mass tolerance $0.5 \mathrm{Da}$; cysteine carboxyamidomethylation static modification (+57.021); dynamic modifications included: oxidation $(+15.995 \mathrm{Da})$ at $\mathrm{M}$, carbamylation $(+43.066 \mathrm{Da})$ at $\mathrm{K}$, acetylation $(+42.011 \mathrm{Da})$ at $\mathrm{K}$, deamidation $(+0.984$ $\mathrm{Da})$ at $\mathrm{N}$ and $\mathrm{Q}$, peptide $\mathrm{N}$-terminus modification of carbamylation $(+43.066 \mathrm{Da})$. The files were searched against the protein sequence database and the decoy database (Percolator node) with a false discovery rate (FDR) of 0.01 .

\section{Label-free quantitation}

LFQ was carried out using PD, which has been demonstrated to perform better in terms of quantifiable low abundance proteome coverage than other search engines (47). The raw files were imported, and each file was assigned to one category from each of 3 study factors: a "grade", either NC or LG or HG; a "patient" number corresponding to biological replicates for each grade (from 1 to 4 for CA tissues and CAderived cell lines, and from 1 to 8 for NC tissues); and a "technical replicate" number for each sample, numbered 1 to 3. Before running the analysis, comparisons were defined as LGCA / NC, HGCA / NC and HGCA / LGCA.

Proteins with a minimum of one unique high-confidence peptide assigned were considered as positive identifications. Protein quantitation grouped abundances were used to calculate the abundance ratio for any given comparison. A t-test was performed by built-in statistical tools in PD to determine the statistical significance for each comparison. The selection criteria for significantly differentially expressed proteins were set at a fold-change $(F C)$ of 2 or greater $\left(\log _{2} F C \geq 1\right)$, and a $p$-value of 0.05 or smaller $\left(-\log _{10} p\right.$ - 
value $\geq 1.30103$ ). These significantly differentially expressed proteins were subsequently analysed for functional enrichments using STRING database (string-db.org) (52).

\section{Functional enrichment analysis}

STRING (string-db.org) (52) was used to create protein-protein interaction networks for the significantly upregulated or downregulated proteins and to identify the GO terms ("biological process", molecular function" and "cellular component") and KEGG and Reactome pathways enriched in these networks. All STRING network analyses were performed with a medium confidence level (0.4). Nodes with no connections to other nodes under these criteria were removed from the map.

\section{Western blotting}

Protein extraction and quantitation were performed as described above, except lysis buffer was Pierce ${ }^{\mathrm{TM}}$ RIPA buffer (cat\# 89901, ThermoFisher Scientific, Waltham, MA, USA).

Protein samples were diluted in 1x Bolt LDS sample buffer (cat\# B0007, ThermoFisher Scientific), heated at $85^{\circ} \mathrm{C}$ for $5 \mathrm{~min}$ and run on Bolt 4-12\% Bis-Tris gels (cat\# NW04125BOX, ThermoFisher Scientific) with $20 \mu \mathrm{g}$ of sample protein per lane, and 1-2 $\mu \mathrm{L}$ of Precision Plus Protein Kaleidoscope MW ladder (cat\# 1610375, Biorad, Auckland, NZ) run in the first lane. Gels were run in Bolt MES SDS Running Buffer (cat\# B0002, ThermoFisher Scientific) for 50 min at 150V, 3.00A and 300W.

Electrophoresed proteins were transferred to PVDF membranes using an iBlot 2 apparatus (cat\# IB21001, ThermoFisher Scientific), briefly washed in water and blocked using iBind Flex FD solution (cat\# SLF2019, ThermoFisher Scientific) before exposure to primary and secondary antibodies in an iBind apparatus (cat\# SLF1000 or SLF2000, ThermoFisher Scientific). Primary antibodies included: a-tubulin (1:2000; cat\# ab7291, Abcam), CD44 (1:5000; cat\# ab157107, Abcam), FN1 (1:500; cat\# ab2413, Abcam), and S100A9 (1:500; cat\# ab92507, Abcam). Secondary antibodies included: HRP-linked goat anti-rabbit (1:1000; cat\# ab6721, Abcam), HRP-linked goat anti-rabbit (1:1000; cat\# 111-035-045, Jackson Immunology), and Alexa Fluor ${ }^{\circledR} 488$ donkey anti-mouse (1:1000; cat\# A-21202, ThermoFisher Scientific). Membranes were incubated in the iBind apparatus for $2.5 \mathrm{~h}$ or overnight. Following incubation, the membranes were briefly washed in water and developed using Clarity Western ECL Substrate (cat\# 170-5061, Biorad). Imaging and densitometry were performed using a ChemiDoc MP Imaging System (Biorad) and ImageLab 6.0 software (Biorad), with the intensity values for the protein-ofinterest normalised against a-tubulin and analysed using GraphPad Prism 8 (San Diego, CA, USA).

\section{Results}

\section{Immunohistochemical staining of tissues}

IHC staining demonstrated the branching crypts of LGCA tumours and the chaotic architecture of the HGCA tumours (Additional File 2). 


\section{DNA sequencing of CA tissues and CA tissue-derived cell lines}

DNA of sufficient quality was isolated from 3 of the 4 LGCA and all 4 HGCA patient-derived tissue and cell line samples, and the DNA samples were analysed by DNA sequencing. The pre-defined Oncomine Tumor Mutation Load w3.2 analysis workflow was launched for each individual tissue and cell line sample, which calculated the tumour mutational burden (TMB) score for each sample, identified and annotated variants within 409 cancer-related genes, and assigned an impact level to each variant. Following this, paired analyses were performed to compare each tissue with its matched cell line.

To confirm whether the mutations detected in the cells were the same as those in the tissues and thereby determine the similarity of the cell lines to their parent tissues, several CA-related genes were selected and the specific mutations within these genes were explored (Table 1). The APC, TP53, KRAS, BRAF, PIK3CA and FBXW7genes were identified by other studies as being relevant to $\mathrm{CRC}(4,27,53)$. MSH2, MSH6 and MLH1 genes are vital to DNA MMR and MSI, and mutations to these genes increase the risk of CRC development by approximate $80 \%(3,4)$.

Table 1: Mutations to CA-related genes in FFPE CA tissues and CA-derived primary cell lines.

\begin{tabular}{|llll|}
\hline Gene & Number of sites mutated & Total mutations & Shared mutations \\
\hline APC & 12 & 41 & 26 \\
\hline TP53 & 7 & 10 & 5 \\
\hline KRAS & 2 & 7 & 4 \\
\hline BRAF & 2 & 4 & 4 \\
\hline MSH2 & 2 & 3 & 3 \\
\hline MSH6 & 11 & 26 & 20 \\
\hline MLH1 & 3 & 8 & 7 \\
\hline PIK3CA & 4 & 11 & 5 \\
\hline FBXW7 & 2 & 2 & 2 \\
\hline
\end{tabular}

DNA sequencing results from 9 key CRC-related genes were analysed in 7 CA tissues and their 7 patientmatched tissue-derived primary cell lines. The number of sites mutated and the total number of mutations across all samples at those sites are listed, as well as the number of mutations that were shared by a tissue sample and its matched cell line. Mutations with low frequency (<6\%) and/or coverage depth (<300 reads), which were unique to 1 sample type (either the tissues or cell lines from a patient, but not both) and/or unique to 1 patient, were considered to be read errors and were disregarded.

The $A P C$ gene was the most commonly mutated, with the $\mathrm{c} .5034 \mathrm{G}>\mathrm{A}$ mutation present in the tissues and cell lines for all 7 samples. A total of 41 APC mutations were identified across all samples at 12 different 
sites (Table 1). Of the 41 mutations, 32 were detected across all tissue samples and 34 across all cell lines, with 26 of these shared by a tissue sample and its matched cell line (Additional File 3). TP53 and MSH6 were also frequently mutated. Half of the total number of mutations detected in the TP53 gene were shared between sample types, and half were only present in the tissues but not in the tissue-derived cell lines. However, there was only one site that was mutated in more than one patient, that being c. 215 $\mathrm{C}>\mathrm{A}$ which was detected in both the tissues and cell lines derived from 4 patients (Additional File 3 ). Similarly, PIK3CA mutations were shared in less than $50 \%$ of cases, due to mutations arising in the cell lines that were absent in the tissues. Overall, 76 out of $112(67.9 \%)$ mutations were shared by the CA tissue samples and the matched CA-derived cell lines based on the analysis of these 9 genes (Table 1). While the CA tissue samples were variable in terms of their unique mutations and TMB scores (Additional File 4), the cell lines derived from them displayed a more consistent number of mutations. The analysis carried out here is similar to another recently performed in meningioma, where the authors expected large variations between cell lines and their parent tissues after 10 passages in culture (54). Therefore, given that the CA-derived cell lines had been in culture for up to 9 passages, the overlap of $67 \%$ of detected mutations between the tissues and cell lines in key CA-related genes suggests that the cell lines are a suitable in vitro model of the tumour tissue.

\section{Protein identification}

A total of 4767 high-confidence proteins were identified across all tissue samples (4 HGCA, 4 LGCA, 8 NC; 3 LC-MS/MS replicates per biological sample), and a total of 4711 high-confidence proteins were identified across cell lines (4 HGCA-derived, 4 LGCA-derived; 3 LC-MS/MS replicates). Of the proteins identified, 3302 proteins were shared by the pooled tissues and pooled cell lines, accounting for $69.3 \%$ and $70.1 \%$ of the proteins identified in the tissues and cell lines, respectively. This was also the case when comparing the proteomes of each primary cell line with its parent tumour tissue sample individually, with around $70 \%$ of proteins detected in one sample type also seen in the other. Complete lists of the proteins identified from tissue samples and from cell lines are available in Additional Files 5 and 6 . The raw LCMS/MS data have been deposited to ProteomeXchange Consortium (55) via the PRIDE (56) partner repository with the dataset identifier PXD024449.

The similarities of biological replicates for each condition were assessed for the tissues and cell lines. The 4 LGCA-derived cell lines shared $56.9 \%$ of identified proteins (Additional File 7A), while the 4 HGCAderived cell lines shared 34.4\% (Additional File 7B). NC tissues from LGCA and HGCA patients shared $31.4 \%$ and $26.9 \%$ of identified proteins, respectively (Additional File 7C,D). The 4 LGCA and 4 HGCA tissues shared $50.7 \%$ and $51.0 \%$ of proteins, respectively (Additional File 7E,F). This reflected the molecular heterogeneity between patients.

One strength of this study is the proteomic analysis of tissue-derived primary cell lines compared to their parent tissues, a point of difference from most proteogenomic studies which tend to analyse tissue samples, commercial cell lines or serum samples. The protein identification data partially corroborated the DNA sequencing data by confirming that the LGCA-derived cell lines had a higher degree of similarity 
to each other than did the tissue samples, representing a purer population compared with the heterogeneous nature of the tissue. However, the HGCA-derived cell lines were the most variable cancer sample group.

\section{Differentially expressed proteins}

LFQ identified proteins that displayed significantly differential expression in LGCA and HGCA tissues versus patient-matched NC tissues, HGCA tissues versus LGCA tissues, and HGCA-derived cell lines versus LGCA-derived cell lines (Table 2). Overall, 318 proteins were significantly upregulated, whereas 362 proteins were significantly downregulated, which represent the proteomic signatures of CA development from the initiation to an advanced stage. The details of these proteins and their quantitation data can be found in Additional File 5 and 6 . Proteins of interest that were selected based on their functions relevant to tumorigenesis, signalling and regulation, and immune responses are listed in Table 3.

Table 2: Number of proteins with significantly different relative abundances between each group (HGCA, LGCA and NC) for CA tissues and CA-derived cell lines.

\begin{tabular}{|c|c|c|c|}
\hline Comparison & & $\begin{array}{l}\text { Number of upregulated } \\
\text { proteins }\end{array}$ & $\begin{array}{l}\text { Number of downregulated } \\
\text { proteins }\end{array}$ \\
\hline \multirow[t]{3}{*}{ Tissues } & $\begin{array}{l}\text { HGCA / } \\
\text { LGCA }\end{array}$ & 97 & 91 \\
\hline & $\begin{array}{l}\text { LGCA / } \\
\text { LGNC }\end{array}$ & 88 & 121 \\
\hline & $\begin{array}{l}\text { HGCA / } \\
\text { HGNC }\end{array}$ & 104 & 168 \\
\hline $\begin{array}{l}\text { Tissue-derived cell } \\
\text { lines }\end{array}$ & $\begin{array}{l}\text { HGCA / } \\
\text { LGCA }\end{array}$ & 137 & 123 \\
\hline
\end{tabular}

All the NC samples are parent-matched with the LGCA or HGCA tumour samples from 8 patients (4 LGCA and 4 HGCA).

Table 3: Selected proteins with differential expression identified in the CA tissues and/or CA tissuederived primary cell lines. 


\begin{tabular}{|c|c|c|c|c|c|c|}
\hline \multirow{3}{*}{$\begin{array}{l}\text { Gene } \\
\text { symbol }\end{array}$} & \multirow[t]{3}{*}{ Protein name } & \multicolumn{4}{|c|}{ Abundance ratio ( $p$-value) } & \multirow{3}{*}{$\begin{array}{l}\text { References } \\
\text { for } \\
\text { involvement } \\
\text { in CA }\end{array}$} \\
\hline & & \multicolumn{3}{|l|}{ Tissues } & \multirow{2}{*}{ 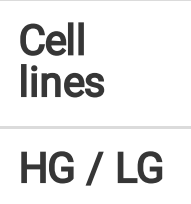 } & \\
\hline & & LG / NC & HG / NC & HG / LG & & \\
\hline ACE2 & $\begin{array}{l}\text { Angiotensin-converting } \\
\text { enzyme } 2\end{array}$ & $\begin{array}{l}100 \\
(<0.001)\end{array}$ & $\begin{array}{l}100 \\
(<0.001)\end{array}$ & $\begin{array}{l}0.725 \\
(0.703)\end{array}$ & - & 97,98 \\
\hline ACSL4 & $\begin{array}{l}\text { Long-chain-fatty-acid- } \\
\text { CoA ligase } 4\end{array}$ & $\begin{array}{l}1.682 \\
(0.993)\end{array}$ & $\begin{array}{l}2.403 \\
(0.996)\end{array}$ & $\begin{array}{l}1.533 \\
(0.946)\end{array}$ & $\begin{array}{l}2.022 \\
(0.01)\end{array}$ & - \\
\hline \multirow[t]{2}{*}{ ANK2 } & \multirow[t]{2}{*}{ Ankyrin-2 } & 0.486 & 0.219 & \multirow{2}{*}{$\begin{array}{l}0.454 \\
(0.056)\end{array}$} & \multirow[t]{2}{*}{-} & \multirow[t]{2}{*}{-} \\
\hline & & $(0.03)$ & $(<0.001)$ & & & \\
\hline AMER3 & $\begin{array}{l}\text { APC membrane } \\
\text { recruitment protein } 3\end{array}$ & - & - & - & $\begin{array}{l}0.485 \\
(0.039)\end{array}$ & - \\
\hline CA1 & Carbonic anhydrase 1 & $\begin{array}{l}1.367 \\
(0.956)\end{array}$ & $\begin{array}{l}0.514 \\
(0.109)\end{array}$ & $\begin{array}{l}0.363 \\
(<0.001)\end{array}$ & - & 119 \\
\hline CA2 & Carbonic anhydrase 2 & $\begin{array}{l}2.358 \\
(0.989)\end{array}$ & $\begin{array}{l}0.757 \\
(0.361)\end{array}$ & $\begin{array}{l}0.31 \\
(<0.001)\end{array}$ & $\begin{array}{l}0.01 \\
(<0.001)\end{array}$ & $118-122$ \\
\hline \multirow[t]{2}{*}{ CA9 } & \multirow[t]{2}{*}{ Carbonic anhydrase 9} & \multirow[t]{2}{*}{-} & 100 & 100 & \multirow[t]{2}{*}{-} & \multirow[t]{2}{*}{118,123} \\
\hline & & & $(<0.001)$ & $(<0.001)$ & & \\
\hline \multirow[t]{2}{*}{ CAV1 } & \multirow[t]{2}{*}{ Caveolin-1 } & \multirow{2}{*}{$\begin{array}{l}0.314 \\
(0.02)\end{array}$} & 0.257 & \multirow{2}{*}{$\begin{array}{l}0.772 \\
(0.385)\end{array}$} & \multirow{2}{*}{$\begin{array}{l}1.303 \\
(0.699)\end{array}$} & \multirow[t]{2}{*}{$57-60$} \\
\hline & & & $(0.004)$ & & & \\
\hline CAV1 & Caveolin-1 isoform 2 & - & - & - & $\begin{array}{l}4.2 \\
(<0.001)\end{array}$ & $57-60$ \\
\hline CAV2 & Caveolin-2 & $\begin{array}{l}0.01 \\
(<0.001)\end{array}$ & $\begin{array}{l}0.01 \\
(<0.001)\end{array}$ & - & $\begin{array}{l}3.015 \\
(0.161)\end{array}$ & 60 \\
\hline CAV3 & Caveolin-3 & - & - & - & $\begin{array}{l}3.809 \\
(<0.001)\end{array}$ & - \\
\hline CD44 & CD44 antigen & $\begin{array}{l}1.705 \\
(0.973)\end{array}$ & $\begin{array}{l}2.263 \\
(0.991)\end{array}$ & $\begin{array}{l}1.264 \\
(0.999)\end{array}$ & $\begin{array}{l}2.269 \\
(<0.001)\end{array}$ & 89 \\
\hline \multirow[t]{2}{*}{ CEACAM5 } & \multirow{2}{*}{$\begin{array}{l}\text { Carcinoembryonic } \\
\text { antigen-related cell } \\
\text { adhesion molecule } 5\end{array}$} & \multirow{2}{*}{$\begin{array}{l}3.713 \\
(0.82)\end{array}$} & 15.18 & 2.573 & \multirow[t]{2}{*}{-} & \multirow[t]{2}{*}{9,10} \\
\hline & & & $(0.05)$ & $(0.03)$ & & \\
\hline \multirow[t]{2}{*}{ CEACAM6 } & Carcinoembryonic & 3.546 & 12.11 & 2.637 & - & 9,10 \\
\hline & $\begin{array}{l}\text { antigen-related cell } \\
\text { adhesion molecule } 6\end{array}$ & & $(0.04)$ & & & \\
\hline CIRH1A & U3 small nucleolar RNA- & 100 & 100 & 1.693 & - & 111 \\
\hline & & $(<0.001)$ & $(<0.001)$ & & & \\
\hline
\end{tabular}




\begin{tabular}{|c|c|c|c|c|c|c|}
\hline CNN1 & Calponin-1 & $\begin{array}{l}0.369 \\
(0.046)\end{array}$ & $\begin{array}{l}0.22 \\
(0.002)\end{array}$ & $\begin{array}{l}0.699 \\
(0.305)\end{array}$ & $\begin{array}{l}0.735 \\
(0.457)\end{array}$ & $115-117$ \\
\hline EXosc1 & $\begin{array}{l}\text { Exosome complex } \\
\text { component csl4 }\end{array}$ & $\begin{array}{l}100 \\
(<0.001)\end{array}$ & $\begin{array}{l}100 \\
(<0.001)\end{array}$ & $\begin{array}{l}1.196 \\
(0.999)\end{array}$ & $\begin{array}{l}0.982 \\
(0.983)\end{array}$ & - \\
\hline EXOSC6 & $\begin{array}{l}\text { Exosome complex } \\
\text { component MTR3 }\end{array}$ & $\begin{array}{l}100 \\
(<0.001)\end{array}$ & $\begin{array}{l}100 \\
(<0.001)\end{array}$ & $\begin{array}{l}1.189 \\
(0.999)\end{array}$ & $\begin{array}{l}1.34 \\
(0.936)\end{array}$ & - \\
\hline FN1 & Fibronectin & $\begin{array}{l}1.429 \\
(0.963)\end{array}$ & $\begin{array}{l}3.32 \\
(0.986)\end{array}$ & $\begin{array}{l}2.358 \\
(0.076)\end{array}$ & $\begin{array}{l}0.35 \\
(<0.001)\end{array}$ & $14,83,84$ \\
\hline GCLM & $\begin{array}{l}\text { Glutamate-cysteine } \\
\text { ligase regulatory subunit }\end{array}$ & - & - & - & $\begin{array}{l}2.723 \\
(0.004)\end{array}$ & - \\
\hline GBP1 & $\begin{array}{l}\text { Guanylate-binding } \\
\text { protein } 1\end{array}$ & - & - & - & $\begin{array}{l}2.197 \\
(0.001)\end{array}$ & 128 \\
\hline HMOX1 & Heme oxygenase- 1 & - & - & - & $\begin{array}{l}3.447 \\
(0.002)\end{array}$ & 103 \\
\hline HPGDS & $\begin{array}{l}\text { Hematopoietic } \\
\text { prostaglandin D } \\
\text { synthase }\end{array}$ & $\begin{array}{l}0.01 \\
(<0.001)\end{array}$ & $\begin{array}{l}0.01 \\
(<0.001)\end{array}$ & - & - & 131,132 \\
\hline LDB3 & $\begin{array}{l}\text { LIM domain-binding } \\
\text { protein } 3\end{array}$ & $\begin{array}{l}0.651 \\
(0.229)\end{array}$ & $\begin{array}{l}0.01 \\
(<0.001)\end{array}$ & $\begin{array}{l}0.01 \\
(<0.001)\end{array}$ & - & - \\
\hline MSH6 & $\begin{array}{l}\text { DNA mismatch repair } \\
\text { protein MSH6 }\end{array}$ & $\begin{array}{l}0.444 \\
(0.024)\end{array}$ & $\begin{array}{l}0.304 \\
(0.001)\end{array}$ & $\begin{array}{l}1.837 \\
(0.775)\end{array}$ & $\begin{array}{l}2.107 \\
(0.422)\end{array}$ & 3,4 \\
\hline MUC1 & Mucin-1 & $\begin{array}{l}1.339 \\
(0.983)\end{array}$ & $\begin{array}{l}5.183 \\
(0.728)\end{array}$ & $\begin{array}{l}5.409 \\
(<0.001)\end{array}$ & - & $67-72$ \\
\hline MUC2 & Mucin-2 & $\begin{array}{l}1.721 \\
(0.989)\end{array}$ & $\begin{array}{l}0.975 \\
(0.634)\end{array}$ & $\begin{array}{l}0.278 \\
(<0.001)\end{array}$ & - & 72 \\
\hline MUC5AC & Mucin-5AC & $\begin{array}{l}100 \\
(<0.001)\end{array}$ & $\begin{array}{l}100 \\
(<0.001)\end{array}$ & $\begin{array}{l}0.446 \\
(0.071)\end{array}$ & - & 74 \\
\hline MUC5B & Mucin-5B & $\begin{array}{l}0.817 \\
(0.473)\end{array}$ & $\begin{array}{l}3.51 \\
(0.935)\end{array}$ & $\begin{array}{l}5.001 \\
(<0.001)\end{array}$ & - & - \\
\hline S100A8 & Protein S100-A8 & $\begin{array}{l}1.66 \\
(0.956)\end{array}$ & $\begin{array}{l}4.417 \\
(0.897)\end{array}$ & $\begin{array}{l}2.434 \\
(0.026)\end{array}$ & - & 21,27 \\
\hline S100A9 & Protein S100-A9 & $\begin{array}{l}1.807 \\
(0.984)\end{array}$ & $\begin{array}{l}4.855 \\
(0.878)\end{array}$ & $\begin{array}{l}2.524 \\
(0.02)\end{array}$ & - & $14,21,27$ \\
\hline SDCBP & Syntenin-1 & $\begin{array}{l}1.565 \\
(0.984)\end{array}$ & $\begin{array}{l}4.929 \\
(0.781)\end{array}$ & $\begin{array}{l}2.798 \\
(0.01)\end{array}$ & $\begin{array}{l}1.547 \\
(0.549)\end{array}$ & 87,88 \\
\hline
\end{tabular}




\begin{tabular}{|lllllll|}
\hline SFRP4 & $\begin{array}{l}\text { Secreted frizzled-related } \\
\text { protein 4 }\end{array}$ & $\begin{array}{l}2.031 \\
(0.963)\end{array}$ & $\begin{array}{l}8.834 \\
(0.093)\end{array}$ & $\begin{array}{l}3.747 \\
(\mathbf{0 . 0 0 8 )}\end{array}$ & - & 86 \\
\hline SMC2 & $\begin{array}{l}\text { Structural maintenance } \\
\text { of chromosomes protein }\end{array}$ & $\begin{array}{l}100 \\
(<0.001)\end{array}$ & $\begin{array}{l}100 \\
(<0.001)\end{array}$ & $\begin{array}{l}2.436 \\
(0.169)\end{array}$ & $\begin{array}{l}1.459 \\
(0.831)\end{array}$ & $91-93$ \\
& 2 & & & & \\
TFRC & $\begin{array}{l}\text { Transferrin receptor } \\
\text { protein-1 }\end{array}$ & $\begin{array}{l}2.621 \\
(0.956)\end{array}$ & $\begin{array}{l}5.358 \\
(0.785)\end{array}$ & $\begin{array}{l}1.847 \\
(0.391)\end{array}$ & $\begin{array}{l}\mathbf{2 . 0 2} \\
\mathbf{( 0 . 0 0 5 )}\end{array}$ & - \\
\hline
\end{tabular}

Values represent the abundance ratios, with $p$-value in brackets. Significantly differential abundance defined as FC $>2$ and $p<0.05$. Numbers in bold represent significant upregulation or downregulation. "-" = not detected.

\section{Functional enrichment analysis of differentially expressed proteins in CA tissues}

The GO terms and KEGG and Reactome pathways enriched in the initiation (NC to LGCA) and progression (LGCA to HGCA) of tumours are summarised in Figure 1. Networks containing proteins or pathways of interest are displayed in Additional Files 8-10.

Relative to NC tissues, the proteins overexpressed in LGCA tissues were enriched for preribosome activity, components of the RNA-degrading exosome complex and intracellular organelles (Figure 1A; Additional File 8A), indicating elevated RNA processing and translational capacity for biosynthesis. Indeed, the data showed that sterol and cholesterol lipid biosynthesis increased (Additional File 8A). Conversely, proteins with significantly decreased abundance in LGCA relative to NC tissues were mainly involved in cytoskeletal organization, cellular component morphogenesis, muscle system processes, and the caveolar macromolecular signalling complex (Figure 4A; Additional File 8B).

The proteins with significant overexpression in HGCA tissues relative to LGCA tissues were enriched for immune system responses, detoxification and cell adhesion (Figure 1B; Additional File 9A). Among this network, FN1 was a key node. Unsurprisingly, enriched GO terms included the positive regulation of cell growth (Figure 1B). HGCA tissues displayed significant decreases relative to LGCA in proteins involved in metabolism of nitrogen, tyrosine and drugs via cytochrome P450 (Figure 1B; Additional File 9B).

\section{Functional analysis of differentially expressed proteins in CA tissue-derived primary cell lines}

Proteins with significantly increased abundance in HGCA cells relative to LGCA cells were enriched for IFN-g and NF-kB signalling, cytokine-mediated signalling, ferroptosis and endocytosis (Figure 1C; Additional File 10A). Key ferroptosis markers present in this network included long-chain-fatty-acid-CoA ligase 4 (ACSL4), transferrin receptor 1 (TFRC), heme oxygenase 1 (HMOX1), and glutamate-cysteine ligase modifier (GCLM). Proteins upregulated in HGCA cell lines that contribute to IFN-g signalling included guanylate-binding protein 1 (GBP1), vascular cell adhesion protein 1 (VCAM1), MHC class I components (HLA-A69, HLA-B), and the proposed stem cell marker CD44. HGCA cell lines displayed significant reductions of membrane-associated proteins including other MHC class I components (HLA- 
A24, HLA-A30, HLA-B41), dystrophin-associated glycoprotein complexes (PGM5, SGCD, SNTB1), filopodia-associated proteins (HLA-G, ITGA3, GAP43), and proteins involved in cell adhesion, cell junctions and cytoskeleton (Figure 1C; Additional File 10B).

\section{Western blotting}

To validate the LC-MS/MS results, western blotting (WB) was performed for the representative selected proteins that had large differences in relative abundance with high statistical significance (Figures 2). Densitometry was carried out on blots, and this method of semi-quantitation was compared with the LCMS/MS quantification data for each individual sample.

FN1 was selected to validate the LC-MS/MS result in cell lines due to significant downregulation in HGCA cell lines relative to LGCA cell lines (Table 3). Densitometry revealed a reduction in HGCA-derived cell lines relative to LGCA-derived cell lines (Figure 2B), with an intensity ratio for HGCA / LGCA of 0.52 (Figure 2C), which was very similar to the abundance ratio for LC-MS/MS (HGCA / LGCA $=0.35)$ (Table 3).

CD44 was selected due to its significant upregulation in HGCA-derived cell lines relative to LGCA cell lines (abundance ratio HGCA / LGCA $=2.27$ ) (Table 3 ) and its relevance as a potential stem cell marker. WB confirmed this trend, with a strong signal detected in the 4 HGCA cell lines, and weaker bands seen in the 4 LGCA cell lines (Figure 2D) at about $75 \mathrm{kDa}$. Densitometry revealed a normalised intensity ratio for HGCA / LGCA of 1.22 (Figure 2F), but this difference was not statistically significant (Figure 2E). However, the WB confirms the result seen in LC-MS/MS, in that CD44 was more abundant in the HGCA-derived cells than in the LGCA-derived cells.

S100A9 was selected because there was a sequential increase in abundance ratio for LGCA / NC (1.81), HGCA / LGCA (2.52) and HGCA / NC (4.86) in the tissue samples (Table 3). This was verified by WB using two LGCA and four HGCA tissues and their patient-matched NC tissue samples (LGNC1-2 and HGNC1-4, respectively). This showed that HGCA tissues had stronger bands for S100A9 at about $13 \mathrm{kDa}$ (Figure $2 \mathrm{G}$ ) than the LGCA tissues, and bands were faint or absent in the NC tissues. Densitometry revealed an HGCA / LGCA abundance ratio of 2.81 (Figure 2I), confirming the upregulation detected by LC-MS/MS with a ratio of 2.52 (Figure 21 , Table 3 ).

\section{Discussion}

\section{DNA sequencing and proteomics validate tumour-derived cell lines}

DNA sequencing was performed to confirm that primary tumour tissue-derived cell lines carried over key mutations present in the parent tumour and did not diverge too far from the parent tissue by accumulating new mutations, in order to assess their suitability as in vitro models of disease.

Inactivating mutations to the $A P C$ gene are the most common mutations in $\mathrm{CRC}(3,4)$. They lead to constitutive Wnt signalling, a process considered to be the initiating factor in CRC development (3). Along with MMR genes such as $M S H 2$ and $M L H 1, A P C$ can be used as a predictive marker of CRC 
development (3). Of the 32 individual mutations to the APC gene detected across the 7 CA tissues, 26 were conserved in the tissue-derived cell lines. There were 4 instances of a mutation detected in only 1 out of 7 CA tissues being lost in the cell line derived from it, and one instance of a mutation arising in only 1 of the 7 cell lines but absent from all other samples, suggesting that these mutations are likely to be sequencing errors. There were two instances of a mutation being detected in both the tissue and cell line of only 1 patient, and these are assumed to be true low-frequency or passenger mutations.

TP53 usually suffers from biallelic deactivation in CRC - one copy mutated and the other lost in a chromosomal deletion (17q), and this loss is associated with malignant transformation (3). It has been suggested that CRC tumours with MMR defects usually retain a wild-type TP53 (3), however the 4 samples in this cohort with the c. 215 C>A TP53 mutation also carried mutations in the MSH2, MSH6 and/or MLH1 genes, suggesting a hypermutated phenotype (4). MSH6 mutations in particular are prevalent in the hypermutated phenotype (4), and these mutations were very common in the LGCA samples (Additional File 3).

Interestingly, the LGCA tumours contained more mutations within these CRC-related genes than HGCA tumours; however, HGCA tumours had larger TMB scores (Additional File 4). This indicates that mutations in these CRC-related genes lead to CRC initiation, and that once the tumour is established and there are mutations present within the MMR genes, a range of other mutations arise that lead to progression of the tumour from LGCA to HGCA or get carried through as passengers.

The high degree of similarity between the tissues and cell lines, in terms of conservation of mutations in key CA-related genes and overlap of their proteomes, lends support to the idea that the cell lines are a reasonable representation of the parent tissue and a suitable in vitro model system. A recent study used a similar methodology to assess the conservation of mutations in primary cell lines derived from meningioma tissues (54).

The proteomes of the LGCA cell lines were less variable than those of the LGCA and HGCA tissues (Additional File 7), reflecting the heterogeneous mix of cell types in tissue, whereas the cell lines are comparatively homogenous. This aligned with the DNA sequencing data, which detected greater variability in terms of mutational burden between tissue samples than between cell lines. The tissue samples include muscle, blood vessels, immune cells and fat, and the process of tumourigenesis leads to large changes due to the loss of normal architecture and function as a dense bulk of tumour cells forms. Accordingly, the CA tissues exhibited significant decreases in proteins involved in muscle structure and contraction (CAV1, CAV2, ANK2, CNN1, TPM1, TPM2, MYL9, MYH11) that were not reflected in the cell lines. The downregulation of muscle system processes was also reported by Vasaikar et al. (27).

\section{Colon adenosarcoma tissues and tissue-derived primary cell lines reveal unique biological functions of tumours}

Analyses of the CA tissues revealed that the transition from NC to LGCA was most strongly characterised by increased preribosome activity, RNA exosome complex components and lipid synthesis and decreases 
in cytoskeletal organisation, caveolar signalling complex and normal colonic function, whereas the progression from LGCA to HGCA was characterised by increased immune signatures and decreased metabolism of nitrogen, tyrosine and drugs.

The caveolar macromolecular signalling complex is comprised of caveolins, which change membrane topology to form caveolae. These membrane structures facilitate trafficking and signal transduction (57). It has been previously reported that caveolin 1 (CAV1) loss is associated with malignant transformation in the colon, and that re-emergence can increase invasion and metastatic potential $(58,59)$. Accordingly, we saw a significant reduction of CAV1 in LGCA and HGCA tissues relative to matched NC tissues and significant upregulation in CAV1 isoform 2 in HGCA-derived cell lines relative to LGCA-derived cell lines. Furthermore, CAV2 was significantly down regulated in LGCA and HGCA tissues relative to NC, and nonsignificantly upregulated in HGCA-derived cell lines CAV2 usually forms a heterodimer with CAV1, so CAV2 loss may be a result of CAV1 loss leading to CAV2 degradation (60). CAV3 is a muscle-specific isoform and its loss leads to muscle degeneration (61). Interestingly, CAV3 was not detected in any tissues, but was significantly overexpressed in HGCA-derived cell lines relative to LGCA-derived cell lines. CAV3 has no previous links to CA, but its expression would be expected to decrease in colon tissues during tumour development as normal muscle structure and function is lost. Further investigation is required to determine the importance of CAV3 in CA.

Lipid biosynthesis has previously been linked to CSCs in colon cancer (62). Cholesterol biosynthesis is upregulated in patient-derived spheroid cultures and required for the maintenance of pluripotency (63). Cholesterol seems to promote CSC activity and persistence by negative regulation of TGF- $\beta$ signalling, and inhibition of cholesterol synthesis has been suggested as a treatment option for CA (63). Similarly, steroids, specifically cholesterol-derived oxysterols, can influence Wnt and MAPK signalling, which are vital to CA development and progression and CSC function (64). Interestingly, CAV1 loss, as described above, causes fatty acid and cholesterol levels in the circulation to increase and the amount stored in the liver to fall due to the impairment to caveolae function at the basolateral membrane of enterocytes in the intestine (65). The upregulation of sterol and cholesterol biosynthesis in the LGCA tissues relative to their NC controls verifies previous findings that indicate their importance in CA, and particularly in CSC activity.

Mucins are highly-glycosylated proteins generally associated with epithelial cells (66). Aberrant glycosylation and expression of mucins is associated with CA $(67,68)$. MUC1 is a transmembrane mucin overexpressed in CA with links to NF-kB-mediated inflammation (69), CSC phenotypes (70) and metastasis (71), and it is under investigation as an immunotherapy target $(68,72)$. In contrast to MUC1, MUC2 suppresses CA and its loss leads to CA development (67). MUC2 and MUC5B are secreted mucins and are the predominant mucins comprising the mucus layer that forms on the lumenal surface of colon epithelial cells (73). MUC5AC upregulation has been linked to the serrated pathway of colon tumourigenesis (74). In line with these reports, MUC1 was significantly upregulated and MUC2 significantly downregulated in HGCA tissues relative to LGCA tissues, MUC5AC was only detected in CA tissues and not NC tissues, and MUC5B was significantly upregulated in HGCA tissues relative to LGCA 
tissues (Table 3). These findings collectively validate mucin expression trends in CA and strengthen the rationale for investigating their utility as biomarkers or potential treatment targets.

Analysis of the cell lines revealed the upregulation of ferroptosis and interferon-gamma (IFN-g)-mediated signalling pathways in HGCA-derived cells relative to LGCA-derived cells (Figure 1C, Additional File 10).

Ferroptosis is a recently recognised form of regulated cell death by iron-dependent lipid peroxidation that causes the cellular membrane damage and the accumulation of reactive lipid hydroperoxides (known as lipid-ROS) to lethal levels (75). Long-chain-fatty-acid-CoA ligase 4 (ACSL4) is an important modulator promoting ferroptosis via enhancing lipid peroxidation $(76,77)$. ACSL4 catalyses the esterification of free fatty acids, preferentially polyunsaturated fatty acids (PUFAs), and incorporates esterified PUFAs into phospholipids within the cell membrane, creating substrates for lipoxygenases for lipid peroxidation. Ferroptosis can be antagonised by neutralising lipid-ROS by coupling the oxidation reaction of glutathione (75). Glutamate-cysteine ligase (GCL), composed of catalytic (GCLC) and modifier (GCLM) subunits, is the rate-limiting enzyme in the glutathione biosynthesis pathway (78). Cellular iron is another factor regulating ferroptosis via the Fenton reaction to produce lipid-ROS, and acts as a cofactor for lipoxygenases that catalyse lipid peroxidation (79). When in circulation, iron forms a complex with transferrin, which binds the transferrin receptor protein-1 (TRFC) on the cell membrane to be taken up by the cell (79). Excess iron can be stored as ferritin or exported from the cell. Ferroptosis can be triggered when there is an excess of iron stored within the cell or when iron uptake is increased (79). In addition, there is evidence that p53 is involved in the regulation of ferroptosis. Xie et al. (80) reported that p53 loss increased the sensitivity of CRC cells to erastin-induced ferroptosis. This was due to the interaction between p53 and dipeptidyl-peptidase-4 (DPP4) - this complex translocates into the nucleus where DPP4 can act as a transcription cofactor. However, in TP53 mutants where p53 is reduced or absent, DPP4 forms a complex with NOX1 to promote lipid peroxidation. TP53 is one the most commonly mutated genes in CRC, and at least one mutation was detected in both the tissues and cell lines from 5 of the 7 samples (Additional File 3). Therefore, in many CRCs there will be a reduction or loss of p53 and a heightened capacity for ferroptosis, supporting the proposal that ferroptosis induction could target CRC cells. All the above results together suggest that ferroptosis may be an effective target for cancer therapies for CRC.

IFN-g is a cytokine produced by immune cells in response to other cytokines or antigen stimulation to drive immune responses (81). It signals via the IFN-g receptor, which is expressed by most, if not all, cell types. Binding of IFN-g to its receptor initiates JAK-STAT signalling, primarily through STAT1 which binds conserved DNA elements called INF-g activation sites to induce the transcription of interferon-stimulated genes (81). The products of these genes regulate chemokine production, MHC molecules, antiviral and antibacterial factors, the function of regulators of metabolism, chromatin and transcription (81). IFN-g upregulates the production of proteasomal subunits and the formation of immunoproteasomes, which produce peptides that bind more efficiently to MHC class I molecules (82). In this way, IFN-g can increase the amount of antigen being presented to immune cells to build an immune response. The IFN-g-induced increase in immunoproteasomes and $\mathrm{MHC}$ class I components may allow 
for greater presentation of cancer antigens to help raise an anti-tumour immune response, and this might indicate a greater chance of immunotherapies being successful. IFN-g signalling was enriched in the HGCA-derived cell lines relative to LGCA-derived cell lines due to significant upregulation of guanylatebinding protein 1 (GBP1), vascular cell adhesion protein 1 (VCAM1), MCH class I components HLA-A and HLA-B, and CD44.

The LGCA tissues displayed decreased cell adhesion (FN1, VTN, VCAM, CEACAM5/6) relative to NC tissues (Figure 1A; Additional File 8B). Conversely, HGCA-derived cell lines displayed upregulation of proteins related to adhesion (CAV1/3, VCAM1, CD44) and cytoskeletal binding (FN1, CDH2) relative to the LGCA-derived cell lines, as previously reported (27) (Figure 1C; Additional File 10A). The observation of differences between the tissues and the cell lines in terms of adhesion and cytoskeletal binding are most likely due to the differences in the costs and benefits of adhesion between in vivo (tumour cell invasion and metastasis) and in vitro (growth as an adherent monolayer) conditions and may be influenced by a cell culture setting that lacks the 3D structural microenvironment present in vivo.

Interestingly, the data for FN1 and for $\mathrm{MCH}$ class I components from the tissues and cell lines were inconsistent. FN1 is one of many ECM proteins with aberrant expression in cancer, where it is associated with angiogenesis, invasion via matrix metalloproteinase activation, self-renewal, proliferation, and resistance to therapy, and high expression correlates with poor survival $(83,84)$. One study demonstrated that silencing FN1 leads to increases in apoptosis-related proteins and reduced NF-kB, suggesting that FN1 overexpression in CA may aid tumour cells to evade apoptosis and to resist therapy by increasing NF-kB anti-apoptotic signalling (84). Interestingly, in line with this finding, proteins involved in the positive regulation of NF-kB signalling such as ferroptosis-related proteins TRFC and HMOX1 were enriched in the HGCA-derived cell lines, despite FN1 being downregulated (Figure 2; Additional File 10B). MHC components HLA-A24, which preferentially presents tumour antigens with an aromatic residue at position 2 and a non-hydrophobic residue at the C-terminus, and HLA-B41, which displays self-peptides with Glu at position 2, were downregulated, whereas HLA-A69, associated with abnormal immune cell accumulation and suppression of the presentation of specific antigens, was upregulated; these factors all suggest a mechanism of immune avoidance by the cancer cells.

The Wnt signalling pathway is heavily implicated in CSC function, and is considered the first pathway to be altered in CA development (3). APC membrane recruitment protein 3 (AMER3), a positive Wnt signalling effector (85), was surprisingly downregulated in the cell lines and not detected in the tissues (Table 3, Additional Files 5 and 6). This may be because the Wnt signalling pathway is already constitutively activated in CA, making these enhancers redundant. Secreted frizzled-related protein 4 (SFRP4), which directly interacts with Wnt proteins and has been suggested as a marker of early-onset colon cancer (86), was overexpressed in CA tissues (Table 3). Furthermore, the cancer-associated scaffold protein syntenin-1 (SDCBP) is known to interact with Wnts (87) and is associated with colon CSC expansion, migration and chemoresistance (88); it was upregulated in HGCA tissues and nonsignificantly increased in the HGCA cell lines (Table 3). CD44 is of particular interest in CRC as it is considered a CSC marker and its transcription is partially mediated through Wnt signalling $(89,90)$. CD44 
upregulation was observed in HGCA-derived cell lines relative to LGCA-derived cell lines (Figure 3; Table 3). CD44 may become a useful prognostic biomarker by aiding in tumour grading and estimating CSC presence. Structural maintenance of chromosomes protein 2 (SMC2) is involved in chromosome stability and DNA packaging as a component of the condensin complex (91-93). The SMC2 gene is a Wnt signalling target, and miRNA silencing of $S M C 2$ reduces intestinal tumour cell proliferation (93). DNA supercoiling is vital to embryonic stem cell survival and SMC2 has been explored as a CSC-specific therapeutic target (92). SMC2 displayed a fold-change increase of approximate 2.5 from LGCA to HGCA, with no detection in the NC cell line or tissues (Table 3), suggesting that its expression may be related to $\mathrm{CA}$ initiation and its upregulation related to progression.

Increases in the LGCA and HGCA tissues, as well as the HGCA-derived cell lines, of proteins involved in immune system processes and drug metabolism (S100A8/S100A9, HLA-A, HLA-B, HLA-DRB1, HLA-DRB5) suggests that changes in the way the cancer cells interact with the immune system, in terms of suppression or avoidance of immune cells and tolerance of inflammation, is involved in tumour initiation and progression. The comparison of the proteomes of CA tissues with patient-matched tissue-derived primary cell lines provides unique insight in this respect. The cell lines, which are a purer population that retain the mutational signatures of the original tumour tissue, represents a unique and powerful method of analysing changes that are more relevant to the signalling within and between tumour cells without being overwhelmed by the large-scale changes occurring across the complexity of a tissue sample. For example, the HGCA cell lines revealed enrichment for IFN-g signalling and ferroptosis not seen in the comparison of NC, LGCA and HGCA tissues, which instead revealed less specific immune-related changes (e.g., "immune system process", "leukocyte-mediated immunity").

Overall, this suggests that within the tissue there are many unique physiological and structural changes occurring that are important aspects of the loss of normal function and the response of the body to the tumour. The primary cell lines supplemented these findings by revealing changes in proteins involved in immune interactions and ferroptosis that went undetected in the tissues.

\section{Potential biomarker candidates and therapeutic drug targets for colorectal cancer}

This study has identified various proteins of interest that warrant further research as potential CA biomarkers, as well as validating some that have previously been identified (Table 3 ). Proteins such as CAV1, CAV2 and CAV3, CA2, CEACAM5/6, CD44, CNN1, FN1, GBP1, HMOX1, HPGDS, MUC1 and MUC2, S100A8/S100A9, SDCBP, SMC2, and SFRP4 were significantly differentially expressed and have been previously reported in CA. However, a range of new protein biomarker candidates for CA including ACE2, ACSL4, AMER3, ANK2, CAV3, EXOSC1, EXOSC6, GCLM, LDB3, MUC5B, and TRFC were found in this study.

ACE2 is a component of the renin-angiotensin system (RAS) that catalyses the production of Mas receptor (MasR) ligands Ang1-9 and Ang1-7 (94). MasR signalling reduces inflammation and susceptibility to cardiovascular diseases (95). ACE2 loss has therefore been predicted to be a marker of poor prognosis in CA $(96,97)$. However, it was detected in only one NC tissue but found at high 
abundance in all LGCA and HGCA tissues (Additional Files 5 and 6). The role of ACE2 and the MasR in cancer is still unclear, with reports of decreased ACE2 in breast and pancreatic cancers (97), but contradictory reports of ACE2 and MasR overexpression in CRC, and MasR-mediated cancer cell migration in renal cell carcinoma $(97,98)$. The Human Protein Atlas supports the finding of elevated ACE2 levels in CRC and suggests that ACE2 is overexpressed in renal, pancreatic and liver cancers (https://www.proteinatlas.org/ENSG00000130234-ACE2/pathology). It is possible that ACE2 plays a role in CRC outside of the RAS, or that the outcomes of MasR signalling depend on their physiological context. The importance of ACE2 in CRC deserves further research.

Ankyrins are adapter proteins that organise integral membrane proteins including cell junction proteins and cell adhesion molecules, ion channels and transporters by anchoring them to the spectrin-based membrane skeleton within the cell (99-101). In particular, ANK2 is known to bind and immobilise L1CAM, attenuating its role in axon outgrowth (102). ANK2 was present in the network of proteins significantly downregulated in LGCA tissues relative to NC. In this network, ANK2 was linked with CACNA1D, a subunit of voltage-dependent calcium channels that confers the "long-lasting (L-type), high-voltage activated" phenotype to the channel. These channels facilitate the movement of calcium ions into cells to allow calcium-dependent processes to occur, including muscle contraction. The loss of ANK2 could reflect the physiological changes that occur in the gut during cancer development, including the loss of muscle in the tumour. Alternatively, low levels of ANK2 would lead to a reduced capacity to anchor other integral membrane proteins to the spectrin skeleton, preventing the collection of multiprotein complexes. This may cause aberrant signalling, either due to members of signalling pathways being unable to group efficiently within the membrane, or alternatively, by allowing proteins that require anchoring to isolate them from a signalling complex to move freely through the membrane and interact with their partners. Defects in such signalling pathways as a result of downregulated ANK2 may contribute to CA development or progression. ANK2 has not yet been associated with CA in the literature and may represent a new biomarker for CA development. Our finding that ANK2 is significantly downregulated in LGCA tissues relative to matched NC suggests that impaired ability to localise and stabilise other transmembrane proteins and interact with adhesion molecules may be implicated in CA progression.

ACSL4 was significantly upregulated in HGCA cell lines relative to LGCA cells lines (Table 3), suggesting that these cells have an elevated potential to undergo ferroptosis (Additional File 10A). Induction of ferroptosis to target therapy-resistant CRC tumour cells has been proposed (76), with ACSL4 potentially representing a novel biomarker for success of this treatment.

TFRC was found to be significantly upregulated in the HGCA cell lines relative to the LGCA cell lines (Table 3), indicating the increased capacity of these cells to take up iron, possible overaccumulation of iron and subsequence of ferroptosis. Furthermore, heme oxygenase 1 (HMOX1), which increases cellular iron levels by metabolising heme, was also found significantly upregulated in these cells. HMOX1 has previously been shown to be expressed in CRC tissues and cell lines (103) and to promote erastin-induced ferroptosis $(104,105)$. TFRC has not been previously linked with CRC but may represent a useful biomarker in this context 
GCLM was significantly upregulated in HGCA cell lines relative to LGCA cell lines (Table 3), indicating that the HGCA cells have a higher capacity for glutathione production to defend against ferroptosis induced by ACSL4, TFRC and HMOX1. Though there is currently no established link between GCLM and CA, this suggests that GCLM could be a potential target for ferroptosis-inducing therapies for CA. GCL inhibition by buthionine sulfoximine has been demonstrated to induce ferroptosis in cultured pancreatic cell lines (106).

LIM domain-binding protein 3 (LDB3), also known as Z-band alternatively spliced PDZ-motif protein (ZASP) or protein cypher, is essential for myofibrillar development and muscle contraction by maintaining the Z-line $(107,108)$. It was detected in LGCA tissues but not expressed in HGCA tissues (Table 3$)$. While LDB1 is associated with cell proliferation and drug resistance in CRC (109), LDB3 has no current links with CA and its loss of expression in HGCA may be useful as a marker for CA progression.

The CA tissues displayed increased levels of preribosomal components (CIRH1A, NIP7, BYSL) and RNA processing members (EXOSC1, EXOSC6). U3 small nucleolar RNA-associated protein 4 (CIRH1A/UTP4) strongly promotes CA cell proliferation and reduces apoptosis (110); it was not detected in NC tissues but was present in CA tissues, and may represent a potential biomarker for CA initiation and a therapeutic target to reduce tumour proliferation. Exosome complex component 6 (EXOSC6) is a non-catalytic component of the RNA exosome complex that performs RNA processing and degradation (111). It is important for cell growth and division and has been implicated in the progression of breast cancer (112). However, its role in CA is undefined. Based on its low expression levels in the NC and stepwise increases in abundance in LGCA and HGCA tissues, it may be a candidate for further research as a potential marker of CA progression.

Calponin-1 (CNN1) regulates smooth muscle contraction by binding actin, calmodulin and tropomyosin $(113,114)$. Downregulation of CNN1 leads to a loss of membrane integrity in smooth muscle, the uterus and peritoneum, causing blood vessels to become leaky and allowing cancer cell intravasation $(115,116)$. CNN1 is considered cancer-suppressive, and indeed it is known to be downregulated in cancers $(115,117)$. It is thought to be a better marker than aSMA for smooth muscle cell differentiation (117). Tumour vasculature has an immature phenotype characterised by incomplete pericyte coverage, irregular shapes and growth patterns, and permeable membranes, which may in part be due to CNN1 loss (117). This allows tumour cells to enter vessels and metastasise (117). In the CA tissues and tissue-derived cell lines, CNN1 levels fell in a stepwise manner from NC to LGCA and LGCA to HGCA. Collectively, CNN1 loss may indicate the initiation of CA and it may represent a useful predictor of invasion and metastatic potential in CA.

Carbonic anhydrases catalyse the interconversion of $\mathrm{CO}_{2}$ and bicarbonate and are crucial for $\mathrm{pH}$ maintenance (118). Carbonic anhydrase 1 (CA1) and 2 (CA2) are found in the cytoplasm of NC mucosal cells (119). CA2 is used as a marker for enterocytes in the human colon (120). CA2 overexpression has been associated with poor prognosis and higher grade in CA patients and is correlated with local and lymphatic invasion in rectal cancer $(118,121)$. Alternatively, CA2 loss has been proposed as a biomarker 
for CRC due to its downregulation in tumours relative to the NC and its inhibitory effect on proliferation when its expression was induced in CRC cell lines (122). CA1 is not detected in most CA cases (119). Both CA1 and CA2 were found to be expressed at low levels in the NC tissues with a non-significant increase in LGCA tissues and subsequent significant reduction in HGCA tissues relative to LGCA and NC, which was also reflected in the HGCA cell lines. This hints at a potential role for CA1 and CA2 loss as markers for progression to HGCA, possibly through loss of enterocytes, meriting further investigation. Similarly, CA9 has been detected in CA and is associated with intestinal stem cells, cellular proliferation and colon carcinogenesis $(118,123)$. CA9 was not detected in the CA cell lines or in NC tissues but was present in LGCA and HGCA tissues, providing further evidence that its expression may be related to CA development.

S100A8 (MRP8) and S100A9 (MRP14) are commonly found as a heterodimer called calprotectin that binds $\mathrm{Ca}^{2+}$ and $\mathrm{Zn}^{2+}$ ions and plays an important role in inflammation caused by infection, autoimmunity or metabolic diseases (124). Together, S100A8 and S100A9 account for almost half of the total protein content of neutrophils and are released to induce chemotaxis of leukocytes, cytokine release and apoptosis (124-126). Expression of S100A8 and S100A9 is upregulated during inflammation, a key aspect of CRC (124). Accordingly, other studies have reported significant overexpression in $\operatorname{CRC}(21,27)$. Similarly, the abundance of S100A9 here was found to increase in a stepwise manner from NC to LGCA and LGCA to HGCA (Figure 4B). Unsurprisingly, they were not detected in the cell lines because they are not produced by the cancer cells themselves, but by neutrophils recruited to the site of the tumour. The detection in the blood of S100A8/S100A9 released by neutrophils in the tumour microenvironment suggests they could be utilised as a serum biomarker for diagnosis or prognosis of CA.

GBP1 expression is induced by IFN-g, and offers broad protection against pathogens via oxidative killing and antimicrobial peptide delivery to autophagosomes (127). The effects of GBP1 on prognosis appear to be context specific. It is overexpressed in inflammatory bowel disease where it is thought to prevent apoptosis in order to maintain barrier function (127). Similarly, it restricts proliferation and apoptosis in cancer, which can establish a senescent, therapy-resistant state (128). Aberrant overexpression of GBP1, induced by INF-g in the inflamed bowel, may be a marker of cells capable of developing resistance to therapy via reduced proliferation and apoptosis.

Hematopoietic prostaglandin D synthase (HPGDS) was expressed at high levels in the NC tissues, but not detected in LGCA or HGCA tissues (Table 3). HPGDS is an enzyme that converts prostaglandin $\mathrm{H}_{2}$ into prostaglandin $\mathrm{D}_{2}$ that functions in smooth muscle contraction and inhibition of platelet aggregation (129). It uses glutathione (GSH) and either $\mathrm{Ca}^{2+}$ or $\mathrm{Mg}^{2+}$ as cofactors (130). In the colon of mice, HPGDS has been shown to reduce inflammation and colitis-associated cancer $(131,132)$, and therefore its loss may be a marker for increased CA risk induced by inflammation.

Functional assays, including miRNA silencing or CRISPR knock-outs, would clarify the roles of these potential CRC biomarkers. 


\section{Conclusions}

Proteomic analysis revealed that when compared to their NC controls, CA tissues displayed increases in preribosome function and RNA processing, and loss of normal muscle function. The alignment of DNA sequencing and LC-MS/MS data from both the CA tissues and CA-derived cell lines and with published data from other CRC proteogenomic studies suggests that patient-derived cell lines are a useful in vitro model for CA tumours, although they are not a complete reflection of the complex situation within CA tissues. The key differences between the two sample types included the global physiological changes such as to muscle structure and drug metabolism that were only seen in the tissue samples, and an increase in IFN-g and ferroptosis-related proteins in HGCA-derived cell lines. This study has highlighted a range of potential CRC protein biomarkers and drug targets including ten novel markers that have not been reported before, such as ferroptosis-related proteins ACSL4, TRFC and GCLM, renin-angiotensin system component ACE2, membrane anchor protein ANK2, muscle contraction-associated protein LDB3, RNA exosome complex component EXOSC6, Wnt effector AMER3, CAV3, and MUCB5. Furthermore, it has validated other CA-related proteins recently reported in the literature, including membrane protein CNN1, enterocyte marker CA2, and calprotectin components S100A8 and S100A9.

\section{Abbreviations}

CA: colon adenocarcinoma

CRC: colorectal cancer

CSC: cancer stem cell

ECM: extracellular matrix

EMT: epithelial-to-mesenchymal transition

FFPE: formalin-fixed paraffin-embedded

GO: gene ontology

HDC: high-energy collision-induced dissociation

HGCA: high-grade colon adenocarcinoma

IHC: immunohistochemical

KEGG: Kyoto encyclopedia of genes and genomes

LFQ: label-free quantitation

LGCA: low-grade colon adenocarcinoma 
MMR: mismatch repair

MSI: microsatellite instability

NC: normal colon

PD: Proteome discoverer

RAS: renin-angiotensin system

TMB: tumour mutational burden

WB: western blotting

\section{Declarations}

\section{Ethics approval and consent to participate}

Human tissue samples and primary cell lines were provided by the Gillies McIndoe Research Institute Tissue Bank (GMRITB) for this study, which was approved by the Central Health and Disability Ethics Committee, Wellington, NZ (Ref. 15/CEN/96) with written informed consent from all patients.

\section{Availability of data}

Mass spectral RAW files and Proteome Discoverer (version 2.4, ThermoFisher Scientific) result files are available on ProteomeXchange Consortium (55) via the PRIDE (56) partner repository with the dataset identifier PXD024449.

\section{Competing interests}

The authors declare no competing interests.

\section{Funding}

Funding from the Lloyd Morrison Trust, GMRI internal funding and Victoria University of Wellington are acknowledged. MJM was supported by a PhD Scholarship from the New Zealand Community Trust.

\section{Authors' contributions}

MJM: study design; data acquisition, analysis and interpretation; draft and revision of manuscript.

SKW: manuscript revision; supervision.

STT: study design; draft and revision of manuscript; provision of materials and resources; supervision. 
LP: study design; data acquisition, analysis and interpretation; draft and revision of manuscript; provision of materials and resources; supervision.

\section{Acknowledgements}

Funding from the Lloyd Morrison Trust, GMRI internal funding, Victoria University of Wellington, and PhD scholarship from the New Zealand Community Trust are acknowledged. MJM was supported by a PhD Scholarship from the New Zealand Community Trust. The authors thank Ms Liz Jones, Ms Erin Paterson and Dr Helen Brasch from the Gillies McIndoe Research Institute for their assistance with IHC staining, generating tissue-derived primary cell lines, and histological characterisation of CA cases, respectively. Thanks to Dr John Groom and colleagues at Hutt Hospital and Wakefield Hospital for their support in facilitating recruitment of tissue samples from their patients to the GMRI Tissue Bank. The mass spectrometry facility and proteomics data processing platform at Victoria University of Wellington (VUW) are acknowledged. We thank Mr Danyl McLauchlan at VUW for maintaining the proteomics software and mass spectrometry data and depositing the proteomics data in ProteomeXchange Consortium. We also thank Dr William T Jordan at VUW for his critiquing the manuscript and useful comments.

\section{References}

1. Ferlay J, Ervik M, Lam F, Colombet M, Mery L, Piñeros M, et al. Global Cancer Observatory: Cancer Today https://gco.iarc.fr/today2020 [Available from: https://gco.iarc.fr/today.

2. Fleming M, Ravula S, Tatishchev SF, Wang HL. Colorectal carcinoma: Pathologic aspects. J Gastrointest Oncol. 2012;3(3):153-73.

3. Markowitz SD, Bertagnolli MM. Molecular origins of cancer: Molecular basis of colorectal cancer. N Engl J Med. 2009;361(25):2449-60.

4. Cancer Genome Atlas N. Comprehensive molecular characterization of human colon and rectal cancer. Nature. 2012;487(7407):330-7.

5. Fearon ER. Molecular genetics of colorectal cancer. Annu Rev Pathol. 2011;6:479-507.

6 . Fidler IJ. The pathogenesis of cancer metastasis: the 'seed and soil' hypothesis revisited. Nat Rev Cancer. 2003;3(6):453-8.

7. Sleeman JP, Nazarenko I, Thiele W. Do all roads lead to Rome? Routes to metastasis development. International Journal of Cancer. 2011;128(11):2511-26.

8. Holme O, Bretthauer M, Fretheim A, Odgaard-Jensen J, Hoff G. Flexible sigmoidoscopy versus faecal occult blood testing for colorectal cancer screening in asymptomatic individuals. Cochrane Database Syst Rev. 2013(9):CD009259.

9. Duffy MJ. Carcinoembryonic antigen as a marker for colorectal cancer: is it clinically useful? Clin Chem. 2001;47(4):624-30.

10. Alves Martins BA, de Bulhoes GF, Cavalcanti IN, Martins MM, de Oliveira PG, Martins AMA. Biomarkers in Colorectal Cancer: The Role of Translational Proteomics Research. Front Oncol. 
2019;9:1284.

11. Idowu MO, Laudadio J, Rizzo K. Diagnostic, Prognostic, and Predictive Molecular Biomarkers and the Utility of Molecular Imaging in Common Gastrointestinal Tumors. Biomed Res Int. 2015;2015:890805.

12. Benson AB, Venook AP, Al-Hawary MM, Cederquist L, Chen YJ, Ciombor KK, et al. NCCN Guidelines Insights: Colon Cancer, Version 2.2018. J Natl Compr Canc Netw. 2018;16(4):359-69.

13. Zhou M, Li M, Liang X, Zhang Y, Huang H, Feng Y, et al. The Significance of Serum S100A9 and TNC Levels as Biomarkers in Colorectal Cancer. J Cancer. 2019;10(22):5315-23.

14. Zheng X, Xu K, Zhou B, Chen T, Huang Y, Li Q, et al. A circulating extracellular vesicles-based novel screening tool for colorectal cancer revealed by shotgun and data-independent acquisition mass spectrometry. J Extracell Vesicles. 2020;9(1):1750202.

15. Ward DG, Suggett N, Cheng Y, Wei W, Johnson H, Billingham LJ, et al. Identification of serum biomarkers for colon cancer by proteomic analysis. Br J Cancer. 2006;94(12):1898-905.

16. Lee CH, Im EJ, Moon PG, Baek MC. Discovery of a diagnostic biomarker for colon cancer through proteomic profiling of small extracellular vesicles. BMC Cancer. 2018;18(1):1058.

17. Mathivanan S, Lim JW, Tauro BJ, Ji H, Moritz RL, Simpson RJ. Proteomics analysis of A33 immunoaffinity-purified exosomes released from the human colon tumor cell line LIM1215 reveals a tissue-specific protein signature. Mol Cell Proteomics. 2010;9(2):197-208.

18. Yuzhalin AE, Gordon-Weeks AN, Tognoli ML, Jones K, Markelc B, Konietzny R, et al. Colorectal cancer liver metastatic growth depends on PAD4-driven citrullination of the extracellular matrix. Nat Commun. 2018;9(1):4783.

19. Meding S, Balluff B, Elsner M, Schone C, Rauser S, Nitsche U, et al. Tissue-based proteomics reveals FXYD3, S100A11 and GSTM3 as novel markers for regional lymph node metastasis in colon cancer. J Pathol. 2012;228(4):459-70.

20. Kim YS, Hwang SY, Kang HY, Sohn H, Oh S, Kim JY, et al. Functional proteomics study reveals that NAcetylglucosaminyltransferase $\mathrm{V}$ reinforces the invasive/metastatic potential of colon cancer through aberrant glycosylation on tissue inhibitor of metalloproteinase-1. Mol Cell Proteomics. 2008;7(1):1-14.

21. Saleem S, Tariq S, Aleem I, Sadr-UI S, Tahseen M, Atiq A, et al. Proteomics analysis of colon cancer progression. Clin Proteomics. 2019;16:44.

22. Mazzanti R, Solazzo M, Fantappie O, Elfering S, Pantaleo P, Bechi P, et al. Differential expression proteomics of human colon cancer. Am J Physiol Gastrointest Liver Physiol. 2006;290(6):G1329-38.

23. Wisniewski JR, Ostasiewicz P, Mann M. High recovery FASP applied to the proteomic analysis of microdissected formalin fixed paraffin embedded cancer tissues retrieves known colon cancer markers. J Proteome Res. 2011;10(7):3040-9.

24. Besson D, Pavageau AH, Valo I, Bourreau A, Belanger A, Eymerit-Morin C, et al. A quantitative proteomic approach of the different stages of colorectal cancer establishes OLFM4 as a new nonmetastatic tumor marker. Mol Cell Proteomics. 2011;10(12):M111 009712. 
25. Chen Y, Ni J, Gao Y, Zhang J, Liu X, Chen Y, et al. Integrated proteomics and metabolomics reveals the comprehensive characterization of antitumor mechanism underlying Shikonin on colon cancer patient-derived xenograft model. Sci Rep. 2020;10(1):14092.

26. Zhang B, Wang J, Wang X, Zhu J, Liu Q, Shi Z, et al. Proteogenomic characterization of human colon and rectal cancer. Nature. 2014;513(7518):382-7.

27. Vasaikar S, Huang C, Wang X, Petyuk VA, Savage SR, Wen B, et al. Proteogenomic Analysis of Human Colon Cancer Reveals New Therapeutic Opportunities. Cell. 2019;177(4):1035-49 e19.

28. Mikula M, Rubel T, Karczmarski J, Goryca K, Dadlez M, Ostrowski J. Integrating proteomic and transcriptomic high-throughput surveys for search of new biomarkers of colon tumors. Funct Integr Genomics. 2011;11(2):215-24.

29. Ma YS, Huang T, Zhong XM, Zhang HW, Cong XL, Xu H, et al. Proteogenomic characterization and comprehensive integrative genomic analysis of human colorectal cancer liver metastasis. Mol Cancer. 2018;17(1):139.

30. Blank-Landeshammer B, Richard VR, Mitsa G, Marques M, LeBlanc A, Kollipara L, et al. Proteogenomics of Colorectal Cancer Liver Metastases: Complementing Precision Oncology with Phenotypic Data. Cancers (Basel). 2019;11(12).

31. Imperial R, Ahmed Z, Toor OM, Erdogan C, Khaliq A, Case P, et al. Comparative proteogenomic analysis of right-sided colon cancer, left-sided colon cancer and rectal cancer reveals distinct mutational profiles. Mol Cancer. 2018;17(1):177.

32. Yue X, Lukowski JK, Weaver EM, Skube SB, Hummon AB. Quantitative Proteomic and Phosphoproteomic Comparison of 2D and 3D Colon Cancer Cell Culture Models. J Proteome Res. 2016;15(12):4265-76.

33. Demory Beckler M, Higginbotham JN, Franklin JL, Ham AJ, Halvey PJ, Imasuen IE, et al. Proteomic analysis of exosomes from mutant KRAS colon cancer cells identifies intercellular transfer of mutant KRAS. Mol Cell Proteomics. 2013;12(2):343-55.

34. Katayama M, Nakano H, Ishiuchi A, Wu W, Oshima R, Sakurai J, et al. Protein pattern difference in the colon cancer cell lines examined by two-dimensional differential in-gel electrophoresis and mass spectrometry. Surg Today. 2006;36(12):1085-93.

35. Zou J, Yu XF, Bao ZJ, Dong J. Proteome of human colon cancer stem cells: a comparative analysis. World J Gastroenterol. 2011;17(10):1276-85.

36. Ludvigsen M, Thorlacius-Ussing L, Vorum H, Moyer MP, Stender MT, Thorlacius-Ussing O, et al. Proteomic Characterization of Colorectal Cancer Cells versus Normal-Derived Colon Mucosa Cells: Approaching Identification of Novel Diagnostic Protein Biomarkers in Colorectal Cancer. Int J Mol Sci. 2020;21(10).

37. Wang J, Mouradov D, Wang X, Jorissen RN, Chambers MC, Zimmerman LJ, et al. Colorectal Cancer Cell Line Proteomes Are Representative of Primary Tumors and Predict Drug Sensitivity. Gastroenterology. 2017;153(4):1082-95. 
38. Ala U, Manco M, Mandili G, Tolosano E, Novelli F, Provero P, et al. Proteomics-Based Evidence for a Pro-Oncogenic Role of ESRP1 in Human Colorectal Cancer Cells. Int J Mol Sci. 2020;21(2).

39. Hu HF, Xu WW, Wang Y, Zheng CC, Zhang WX, Li B, et al. Comparative Proteomics Analysis Identifies Cdc42-Cdc42BPA Signaling as Prognostic Biomarker and Therapeutic Target for Colon Cancer Invasion. J Proteome Res. 2018;17(1):265-75.

40. Zhao L, Liu L, Wang S, Zhang YF, Yu L, Ding YQ. Differential proteomic analysis of human colorectal carcinoma cell lines metastasis-associated proteins. J Cancer Res Clin Oncol. 2007;133(10):771-82.

41. Schunter AJ, Yue X, Hummon AB. Phosphoproteomics of colon cancer metastasis: comparative mass spectrometric analysis of the isogenic primary and metastatic cell lines SW480 and SW620. Anal Bioanal Chem. 2017;409(7):1749-63.

42. Torres S, Garcia-Palmero I, Marin-Vicente C, Bartolome RA, Calvino E, Fernandez-Acenero MJ, et al. Proteomic Characterization of Transcription and Splicing Factors Associated with a Metastatic Phenotype in Colorectal Cancer. J Proteome Res. 2018;17(1):252-64.

43. Van Houdt WJ, Emmink BL, Pham TV, Piersma SR, Verheem A, Vries RG, et al. Comparative proteomics of colon cancer stem cells and differentiated tumor cells identifies BIRC6 as a potential therapeutic target. Mol Cell Proteomics. 2011;10(12):M111 011353.

44. Demmers LC, Kretzschmar K, Van Hoeck A, Bar-Epraim YE, van den Toorn HWP, Koomen M, et al. Single-cell derived tumor organoids display diversity in HLA class I peptide presentation. Nat Commun. 2020;11(1):5338.

45. Codrich M, Dalla E, Mio C, Antoniali G, Malfatti MC, Marzinotto S, et al. Integrated multi-omics analyses on patient-derived CRC organoids highlight altered molecular pathways in colorectal cancer progression involving PTEN. J Exp Clin Cancer Res. 2021;40(1):198.

46. Michels BE, Mosa MH, Grebbin BM, Yepes D, Darvishi T, Hausmann J, et al. Human colon organoids reveal distinct physiologic and oncogenic Wnt responses. J Exp Med. 2019;216(3):704-20.

47. Zhao L, Cong X, Zhai L, Hu H, Xu JY, Zhao W, et al. Comparative evaluation of label-free quantification strategies. J Proteomics. 2020;215:103669.

48. Xu JY, Zhang C, Wang X, Zhai L, Ma Y, Mao Y, et al. Integrative Proteomic Characterization of Human Lung Adenocarcinoma. Cell. 2020;182(1):245-61 e17.

49. Munro MJ, Wickremesekera SK, Peng L, Marsh RW, Itinteang T, Tan ST. Cancer stem cell subpopulations in primary colon adenocarcinoma. PLoS One. 2019;14(9):e0221963.

50. Peng L, Kapp EA, Fenyo D, Kwon MS, Jiang P, Wu S, et al. The Asia Oceania Human Proteome Organisation Membrane Proteomics Initiative. Preparation and characterisation of the carbonatewashed membrane standard. Proteomics. 2010;10(22):4142-8.

51. Peng L, Kapp EA, McLauchlan D, Jordan TW. Characterization of the Asia Oceania Human Proteome Organisation Membrane Proteomics Initiative Standard using SDS-PAGE shotgun proteomics. Proteomics. 2011;11(22):4376-84.

52. Szklarczyk D, Gable AL, Lyon D, Junge A, Wyder S, Huerta-Cepas J, et al. STRING v11: protein-protein association networks with increased coverage, supporting functional discovery in genome-wide 
experimental datasets. Nucleic Acids Res. 2019;47(D1):D607-D13.

53. Dos Santos W, Sobanski T, de Carvalho AC, Evangelista AF, Matsushita M, Berardinelli GN, et al. Mutation profiling of cancer drivers in Brazilian colorectal cancer. Sci Rep. 2019;9(1):13687.

54. Kim E, Kim M, So K, Park YS, Woo CG, Hyun SH. Characterization and comparison of genomic profiles between primary cancer cell lines and parent atypical meningioma tumors. Cancer Cell Int. 2020;20:345.

55. Deutsch EW, Csordas A, Sun Z, Jarnuczak A, Perez-Riverol Y, Ternent T, et al. The ProteomeXchange consortium in 2017: supporting the cultural change in proteomics public data deposition. Nucleic Acids Res. 2017;45(D1):D1100-D6.

56. Perez-Riverol Y, Csordas A, Bai J, Bernal-Llinares M, Hewapathirana S, Kundu DJ, et al. The PRIDE database and related tools and resources in 2019: improving support for quantification data. Nucleic Acids Res. 2019;47(D1):D442-D50.

57. Zhao Z, Han FH, Yang SB, Hua LX, Wu JH, Zhan WH. Loss of stromal caveolin-1 expression in colorectal cancer predicts poor survival. World J Gastroenterol. 2015;21(4):1140-7.

58. Campos A, Burgos-Ravanal R, Gonzalez MF, Huilcaman R, Lobos Gonzalez L, Quest AFG. Cell Intrinsic and Extrinsic Mechanisms of Caveolin-1-Enhanced Metastasis. Biomolecules. 2019;9(8).

59. Diaz MI, Diaz P, Bennett JC, Urra H, Ortiz R, Orellana PC, et al. Caveolin-1 suppresses tumor formation through the inhibition of the unfolded protein response. Cell Death Dis. 2020;11(8):648.

60. Drab M, Verkade P, Elger M, Kasper M, Lohn M, Lauterbach B, et al. Loss of caveolae, vascular dysfunction, and pulmonary defects in caveolin-1 gene-disrupted mice. Science. 2001;293(5539):2449-52.

61. Hagiwara Y, Sasaoka T, Araishi K, Imamura M, Yorifuji H, Nonaka I, et al. Caveolin-3 deficiency causes muscle degeneration in mice. Hum Mol Genet. 2000;9(20):3047-54.

62. Hao JJ, Zhi X, Wang Y, Zhang Z, Hao Z, Ye R, et al. Comprehensive Proteomic Characterization of the Human Colorectal Carcinoma Reveals Signature Proteins and Perturbed Pathways. Sci Rep. 2017;7:42436.

63. Gao S, Soares F, Wang S, Wong CC, Chen H, Yang Z, et al. CRISPR screens identify cholesterol biosynthesis as a therapeutic target on stemness and drug resistance of colon cancer. Oncogene. 2021;40(48):6601-13.

64. Kloudova A, Guengerich FP, Soucek P. The Role of Oxysterols in Human Cancer. Trends Endocrinol Metab. 2017;28(7):485-96.

65. Otis JP, Shen MC, Quinlivan V, Anderson JL, Farber SA. Intestinal epithelial cell caveolin 1 regulates fatty acid and lipoprotein cholesterol plasma levels. Dis Model Mech. 2017;10(3):283-95.

66. Gendler SJ, Spicer AP. Epithelial mucin genes. Annu Rev Physiol. 1995;57:607-34.

67. Velcich A, Yang W, Heyer J, Fragale A, Nicholas C, Viani S, et al. Colorectal cancer in mice genetically deficient in the mucin Muc2. Science. 2002;295(5560):1726-9. 
68. Kasprzak A, Siodla E, Andrzejewska M, Szmeja J, Seraszek-Jaros A, Cofta S, et al. Differential expression of mucin 1 and mucin 2 in colorectal cancer. World J Gastroenterol. 2018;24(36):416477.

69. Takahashi H, Jin C, Rajabi H, Pitroda S, Alam M, Ahmad R, et al. MUC1-C activates the TAK1 inflammatory pathway in colon cancer. Oncogene. 2015;34(40):5187-97.

70. Li W, Zhang N, Jin C, Long MD, Rajabi H, Yasumizu Y, et al. MUC1-C drives stemness in progression of colitis to colorectal cancer. JCI Insight. 2020;5(12).

71. Zeng Y, Zhang Q, Zhang Y, Lu M, Liu Y, Zheng T, et al. MUC1 Predicts Colorectal Cancer Metastasis: A Systematic Review and Meta-Analysis of Case Controlled Studies. PLoS One. 2015;10(9):e0138049.

72. Guo M, You C, Dou J. Role of transmembrane glycoprotein mucin 1 (MUC1) in various types of colorectal cancer and therapies: Current research status and updates. Biomed Pharmacother. 2018;107:1318-25.

73. Linden SK, Sutton P, Karlsson NG, Korolik V, McGuckin MA. Mucins in the mucosal barrier to infection. Mucosal Immunol. 2008;1(3):183-97.

74. Walsh MD, Clendenning M, Williamson E, Pearson SA, Walters RJ, Nagler B, et al. Expression of MUC2, MUC5AC, MUC5B, and MUC6 mucins in colorectal cancers and their association with the CpG island methylator phenotype. Mod Pathol. 2013;26(12):1642-56.

75. Dixon SJ, Lemberg KM, Lamprecht MR, Skouta R, Zaitsev EM, Gleason CE, et al. Ferroptosis: an irondependent form of nonapoptotic cell death. Cell. 2012;149(5):1060-72.

76. Wu J, Minikes AM, Gao M, Bian H, Li Y, Stockwell BR, et al. Intercellular interaction dictates cancer cell ferroptosis via NF2-YAP signalling. Nature. 2019;572(7769):402-6.

77. Cui Y, Zhang Y, Zhao X, Shao L, Liu G, Sun C, et al. ACSL4 exacerbates ischemic stroke by promoting ferroptosis-induced brain injury and neuroinflammation. Brain Behav Immun. 2021;93:312-21.

78. Lu SC. Glutathione synthesis. Biochim Biophys Acta. 2013;1830(5):3143-53.

79. Xu S, He Y, Lin L, Chen P, Chen M, Zhang S. The emerging role of ferroptosis in intestinal disease. Cell Death Dis. 2021;12(4):289.

80. Xie Y, Zhu S, Song X, Sun X, Fan Y, Liu J, et al. The Tumor Suppressor p53 Limits Ferroptosis by Blocking DPP4 Activity. Cell Rep. 2017;20(7):1692-704.

81. Ivashkiv LB. IFNgamma: signalling, epigenetics and roles in immunity, metabolism, disease and cancer immunotherapy. Nat Rev Immunol. 2018;18(9):545-58.

82. Arellano-Garcia ME, Misuno K, Tran SD, Hu S. Interferon-gamma induces immunoproteasomes and the presentation of MHC I-associated peptides on human salivary gland cells. PLoS One. 2014;9(8):e102878.

83. Wang JP, Hielscher A. Fibronectin: How Its Aberrant Expression in Tumors May Improve Therapeutic Targeting. J Cancer. 2017;8(4):674-82.

84. Yi W, Xiao E, Ding R, Luo P, Yang Y. High expression of fibronectin is associated with poor prognosis, cell proliferation and malignancy via the NF-kappaB/p53-apoptosis signaling pathway in colorectal 
cancer. Oncol Rep. 2016;36(6):3145-53.

85. Brauburger K, Akyildiz S, Ruppert JG, Graeb M, Bernkopf DB, Hadjihannas MV, et al. Adenomatous polyposis coli (APC) membrane recruitment 3, a member of the APC membrane recruitment family of APC-binding proteins, is a positive regulator of Wnt-beta-catenin signalling. FEBS J. 2014;281(3):787-801.

86. Nfonsam LE, Jandova J, Jecius HC, Omesiete PN, Nfonsam VN. SFRP4 expression correlates with epithelial mesenchymal transition-linked genes and poor overall survival in colon cancer patients. World J Gastrointest Oncol. 2019;11(8):589-98.

87. Kashyap R, Roucourt B, Lembo F, Fares J, Carcavilla AM, Restouin A, et al. Syntenin controls migration, growth, proliferation, and cell cycle progression in cancer cells. Front Pharmacol. 2015;6:241.

88. Iwamoto K, Takahashi H, Okuzaki D, Osawa H, Ogino T, Miyoshi N, et al. Syntenin-1 promotes colorectal cancer stem cell expansion and chemoresistance by regulating prostaglandin E2 receptor. Br J Cancer. 2020;123(6):955-64.

89. Jaggupilli A, Elkord E. Significance of CD44 and CD24 as cancer stem cell markers: an enduring ambiguity. Clin Dev Immunol. 2012;2012:708036.

90. Wielenga VJ, Smits R, Korinek V, Smit L, Kielman M, Fodde R, et al. Expression of CD44 in Apc and Tcf mutant mice implies regulation by the WNT pathway. Am J Pathol. 1999;154(2):515-23.

91. Je EM, Yoo NJ, Lee SH. Mutational and expressional analysis of SMC2 gene in gastric and colorectal cancers with microsatellite instability. APMIS. 2014;122(6):499-504.

92. Montero S, Seras-Franzoso J, Andrade F, Martinez-Trucharte F, Vilar-Hernandez M, Quesada M, et al. Intracellular Delivery of Anti-SMC2 Antibodies against Cancer Stem Cells. Pharmaceutics. 2020;12(2).

93. Davalos V, Suarez-Lopez L, Castano J, Messent A, Abasolo I, Fernandez Y, et al. Human SMC2 protein, a core subunit of human condensin complex, is a novel transcriptional target of the WNT signaling pathway and a new therapeutic target. J Biol Chem. 2012;287(52):43472-81.

94. Fountain JH, Lappin SL. Physiology, Renin Angiotensin System. StatPearls. Treasure Island (FL)2019.

95. Sparks MA, Crowley SD, Gurley SB, Mirotsou M, Coffman TM. Classical Renin-Angiotensin system in kidney physiology. Compr Physiol. 2014;4(3):1201-28.

96. Duan Y, Beli E, Li Calzi S, Quigley JL, Miller RC, Moldovan L, et al. Loss of Angiotensin-Converting Enzyme 2 Exacerbates Diabetic Retinopathy by Promoting Bone Marrow Dysfunction. Stem Cells. 2018;36(9):1430-40.

97. Xu J, Fan J, Wu F, Huang Q, Guo M, Lv Z, et al. The ACE2/Angiotensin-(1-7)/Mas Receptor Axis: Pleiotropic Roles in Cancer. Front Physiol. 2017;8:276.

98. Bernardi S, Zennaro C, Palmisano S, Velkoska E, Sabato N, Toffoli B, et al. Characterization and significance of ACE2 and Mas receptor in human colon adenocarcinoma. J Renin Angiotensin Aldosterone Syst. 2012;13(1):202-9. 
99. Bennett V, Baines AJ. Spectrin and ankyrin-based pathways: metazoan inventions for integrating cells into tissues. Physiol Rev. 2001;81(3):1353-92.

100. Otto $E$, Kunimoto $M, M c L a u g h l i n ~ T$, Bennett V. Isolation and characterization of cDNAs encoding human brain ankyrins reveal a family of alternatively spliced genes. J Cell Biol. 1991;114(2):241-53.

101. Bennett V, Healy J. Membrane domains based on ankyrin and spectrin associated with cell-cell interactions. Cold Spring Harb Perspect Biol. 2009;1(6):a003012.

102. Gil OD, Sakurai T, Bradley AE, Fink MY, Cassella MR, Kuo JA, et al. Ankyrin binding mediates L1CAM interactions with static components of the cytoskeleton and inhibits retrograde movement of L1CAM on the cell surface. J Cell Biol. 2003;162(4):719-30.

103. Yin H, Fang J, Liao L, Maeda H, Su Q. Upregulation of heme oxygenase-1 in colorectal cancer patients with increased circulation carbon monoxide levels, potentially affects chemotherapeutic sensitivity. BMC Cancer. 2014;14:436.

104. Kwon MY, Park E, Lee SJ, Chung SW. Heme oxygenase-1 accelerates erastin-induced ferroptotic cell death. Oncotarget. 2015;6(27):24393-403.

105. Menon AV, Liu J, Tsai HP, Zeng L, Yang S, Asnani A, et al. Excess heme upregulates heme oxygenase 1 and promotes cardiac ferroptosis in mice with sickle cell disease. Blood. 2021.

106. Nishizawa S, Araki H, Ishikawa Y, Kitazawa S, Hata A, Soga T, et al. Low tumor glutathione level as a sensitivity marker for glutamate-cysteine ligase inhibitors. Oncol Lett. 2018;15(6):8735-43.

107. Leung MC, Hitchen PG, Ward DG, Messer AE, Marston SB. Z-band alternatively spliced PDZ motif protein (ZASP) is the major O-linked beta- $\mathrm{N}$-acetylglucosamine-substituted protein in human heart myofibrils. J Biol Chem. 2013;288(7):4891-8.

108. Zhou Q, Chu PH, Huang C, Cheng CF, Martone ME, Knoll G, et al. Ablation of Cypher, a PDZ-LIM domain Z-line protein, causes a severe form of congenital myopathy. J Cell Biol. 2001;155(4):60512.

109. Zhu M, Jiang B, Zuo H, Wang X, Ge H, Huang Z. LIM-Domain-Binding Protein 1 Mediates Cell Proliferation and Drug Resistance in Colorectal Cancer. Front Surg. 2021;8:790380.

110. Guo F, Chen JJ, Tang WJ. CIRH1A augments the proliferation of RKO colorectal cancer cells. Oncol Rep. 2017;37(4):2375-81.

111. Xie B, Becker E, Stuparevic I, Wery M, Szachnowski U, Morillon A, et al. The anti-cancer drug 5fluorouracil affects cell cycle regulators and potential regulatory long non-coding RNAs in yeast. RNA Biol. 2019;16(6):727-41.

112. Hawkins OE, Vangundy RS, Eckerd AM, Bardet W, Buchli R, Weidanz JA, et al. Identification of breast cancer peptide epitopes presented by HLA-A*0201. J Proteome Res. 2008;7(4):1445-57.

113. Winder SJ, Walsh MP. Smooth muscle calponin. Inhibition of actomyosin MgATPase and regulation by phosphorylation. J Biol Chem. 1990;265(17):10148-55.

114. Winder SJ, Walsh MP. Calponin: thin filament-linked regulation of smooth muscle contraction. Cell Signal. 1993;5(6):677-86. 
115. Taniguchi S. Suppression of cancer phenotypes through a multifunctional actin-binding protein, calponin, that attacks cancer cells and simultaneously protects the host from invasion. Cancer Sci. 2005;96(11):738-46.

116. Taniguchi S, Takeoka M, Ehara T, Hashimoto S, Shibuki H, Yoshimura N, et al. Structural fragility of blood vessels and peritoneum in calponin h1-deficient mice, resulting in an increase in hematogenous metastasis and peritoneal dissemination of malignant tumor cells. Cancer Res. 2001;61(20):7627-34.

117. Yanagisawa $\mathrm{Y}$, Takeoka M, Ehara T, Itano N, Miyagawa S, Taniguchi S. Reduction of Calponin h1 expression in human colon cancer blood vessels. Eur J Surg Oncol. 2008;34(5):531-7.

118. Viikila P, Kivela AJ, Mustonen H, Koskensalo S, Waheed A, Sly WS, et al. Carbonic anhydrase enzymes II, VII, IX and XII in colorectal carcinomas. World J Gastroenterol. 2016;22(36):8168-77.

119. Mori M, Staniunas RJ, Barnard GF, Jessup JM, Steele GD, Jr., Chen LB. The significance of carbonic anhydrase expression in human colorectal cancer. Gastroenterology. 1993;105(3):820-6.

120. Bekku S, Mochizuki H, Takayama E, Shinomiya N, Fukamachi H, Ichinose M, et al. Carbonic anhydrase I and II as a differentiation marker of human and rat colonic enterocytes. Res Exp Med (Berl). 1998;198(4):175-85.

121. Bekku S, Mochizuki H, Yamamoto T, Ueno H, Takayama E, Tadakuma T. Expression of carbonic anhydrase I or II and correlation to clinical aspects of colorectal cancer. Hepatogastroenterology. 2000;47(34):998-1001.

122. Zhou R, Huang W, Yao Y, Wang Y, Li Z, Shao B, et al. CA II, a potential biomarker by proteomic analysis, exerts significant inhibitory effect on the growth of colorectal cancer cells. Int J Oncol. 2013;43(2):611-21.

123. Takahashi H, Suzuki Y, Nishimura J, Haraguchi N, Ohtsuka M, Miyazaki S, et al. Characteristics of carbonic anhydrase 9 expressing cells in human intestinal crypt base. Int J Oncol. 2016;48(1):11522.

124. Wang S, Song R, Wang Z, Jing Z, Wang S, Ma J. S100A8/A9 in Inflammation. Front Immunol. 2018;9:1298.

125. Nakatani Y, Yamazaki M, Chazin WJ, Yui S. Regulation of S100A8/A9 (calprotectin) binding to tumor cells by zinc ion and its implication for apoptosis-inducing activity. Mediators Inflamm. 2005;2005(5):280-92.

126. Ryckman C, Vandal K, Rouleau P, Talbot M, Tessier PA. Proinflammatory activities of S100: proteins S100A8, S100A9, and S100A8/A9 induce neutrophil chemotaxis and adhesion. J Immunol. 2003;170(6):3233-42.

127. Schnoor M, Betanzos A, Weber DA, Parkos CA. Guanylate-binding protein-1 is expressed at tight junctions of intestinal epithelial cells in response to interferon-gamma and regulates barrier function through effects on apoptosis. Mucosal Immunol. 2009;2(1):33-42.

128. Honkala AT, Tailor D, Malhotra SV. Guanylate-Binding Protein 1: An Emerging Target in Inflammation and Cancer. Front Immunol. 2019;10:3139. 
129. Ito S, Narumiya S, Hayaishi O. Prostaglandin D2: a biochemical perspective. Prostaglandins Leukot Essent Fatty Acids. 1989;37(4):219-34.

130. Rittchen S, Heinemann A. Therapeutic Potential of Hematopoietic Prostaglandin D2 Synthase in Allergic Inflammation. Cells. 2019;8(6).

131. Iwanaga K, Nakamura T, Maeda S, Aritake K, Hori M, Urade Y, et al. Mast cell-derived prostaglandin D2 inhibits colitis and colitis-associated colon cancer in mice. Cancer Res. 2014;74(11):3011-9.

132. Park JM, Kanaoka Y, Eguchi N, Aritake K, Grujic S, Materi AM, et al. Hematopoietic prostaglandin D synthase suppresses intestinal adenomas in ApcMin/+ mice. Cancer Res. 2007;67(3):881-9.

\section{Figures}

\section{Figure 1}

Functional enrichments of proteins with significantly differential abundance in colorectal adenocarcinoma. A, LGCA v LGNC tissues. B, HGCA v HGCA tissues. C, HGCA v LGCA cell lines. The analyses were performed using STRING online software with a medium confidence level (0.4), providing the significantly enriched GO terms, KEGG and Reactome pathways. The vertical axis displays the significantly enriched biological functions. The horizontal axis indicates the strength of enrichment, which is the log10(observed/expected proteins in the network that are annotated with a term) and measures how large the enrichment effect is. The higher the absolute value of the strength, the stronger the impact. Positive strength values indicate enrichment amongst significantly upregulated proteins, negative strength values indicate enrichment amongst significantly downregulated proteins. The lists of differentially expressed proteins used to create these graphs are found in Additional Files 5 and 6 . Colour codes: the green denotes KEGG and Reactome Pathways; the orange and blue code GO Cellular Component and Biological Process categories, respectively.

\section{Figure 2}

Western blotting for FN1 and CD44 proteins extracted from CA-derived cell line samples and S100A9 from CA tissue samples. Fluorescent signals for FN1 (A; red), CD44 (D; red) and S100A9 (G; red), and the loading control a-tubulin (A,D,G; green). Means and standard deviations of normalised signal densities of FN1 (B), CD44 (E) and S100A9 (H) against their corresponding a-tubulin bands. Comparison of abundance ratios for HGCA / LGCA as detected by LC-MS/MS and western blotting (WB) for FN1 (C), CD44 (F) and S100A9 (I).

\section{Supplementary Files}


This is a list of supplementary files associated with this preprint. Click to download.

- AdditinalFile1.docx

- AdditinalFile2.docx

- AdditionalFiles3.docx

- AdditionalFiles4.docx

- AdditionalFile5.xIsx

- AdditionalFile6.xIsx

- AdditionalFile7.docx

- AdditionalFiles8.pptx

- AdditionalFiles9.pptx

- AdditionalFiles10.pptx 